\title{
Investigations of Pasteuria and the Root-Lesion Nematode Pratylenchus penetrans in Soils Collected from Certified Organic Farms in the Mid-Atlantic United States
}

Tiara Nicole King

Follow this and additional works at: https://researchrepository.wvu.edu/etd

\section{Recommended Citation}

King, Tiara Nicole, "Investigations of Pasteuria and the Root-Lesion Nematode Pratylenchus penetrans in Soils Collected from Certified Organic Farms in the Mid-Atlantic United States" (2015). Graduate Theses, Dissertations, and Problem Reports. 5981.

https://researchrepository.wvu.edu/etd/5981

This Thesis is protected by copyright and/or related rights. It has been brought to you by the The Research Repository @ WVU with permission from the rights-holder(s). You are free to use this Thesis in any way that is permitted by the copyright and related rights legislation that applies to your use. For other uses you must obtain permission from the rights-holder(s) directly, unless additional rights are indicated by a Creative Commons license in the record and/ or on the work itself. This Thesis has been accepted for inclusion in WVU Graduate Theses, Dissertations, and Problem Reports collection by an authorized administrator of The Research Repository @ WVU. For more information, please contact researchrepository@mail.wvu.edu. 
Investigations of Pasteuria and the Root-Lesion Nematode Pratylenchus penetrans in Soils Collected from Certified Organic Farms in the Mid-Atlantic United States

\author{
Tiara Nicole King
}

\begin{abstract}
Thesis submitted to the
Davis College of Agriculture, Natural Resources and Design

at West Virginia University

in partial fulfillment of the requirements for the degree of
\end{abstract}

Master of Science in

Plant and Soil Science

with an emphasis in Plant Pathology

\author{
James B. Kotcon, Ph.D., Chair \\ Louis M. McDonald, Ph.D. \\ Joseph B. Morton, Ph.D. \\ Alan J. Sexstone, Ph.D. \\ Division of Plant and Soil Sciences \\ Morgantown, West Virginia \\ 2015
}

Keywords: bacterial parasite, biological control, certified organic, green bean, Mid-Atlantic, organic agriculture, organic farm survey, Pasteuria, Phaseolus vulgaris, plant-parasitic nematode, Pratylenchus, root lesion nematode, soil suppression

Copyright 2015 Tiara Nicole King 


\begin{abstract}
Investigations of Pasteuria and the Root-Lesion Nematode Pratylenchus penetrans in Soils Collected from Certified Organic Farms in the Mid-Atlantic United States
\end{abstract}

\title{
Tiara Nicole King
}

Occurrence of lesion nematodes and Pasteuria, an obligate bacterial parasite, was surveyed in 34 soils collected from certified organic farms in the Mid-Atlantic United States. Pasteuria endospores were observed on Pratylenchus crenatus in six of 22 soils. Population density of Pratylenchus in soils lacking signs of Pasteuria correlated positively with soil $\mathrm{pH}$, cation exchange capacity, and concentration of phosphorus pentoxide and calcium. Pasteuria was detected on Pratylenchus in nematode suppressive soils at the West Virginia University Organic Research Farm. Interactions between Pasteuria and Pratylenchus penetrans were studied in two laboratory bench-top experiments. Soil treatment effects on reproduction of Pratylenchus penetrans on green bean (Phaseolus vulgaris) cv. Jade in soils with Pasteuria were compared. Sterile and non-sterile Organic Research Farm soil treatments were planted with Phaseolus vulgaris cv. Jade and three of four treatments were inoculated with Pratylenchus penetrans. Mean population densities of Pratylenchus were significantly different among soil treatments ( $\mathrm{P}>0.0001)$ and Pasteuria endospores were observed on Pratylenchus crenatus from a control treatment. Twelve soils from the survey samples, six with and six without Pasteuria endospores detected on lesion nematodes, were used to compare eight soil treatment combinations in three randomized blocks. Treatment combinations consisted of soil type, time of harvest, presence of Pasteuria, and lesion nematode inoculation. Populations of Pratylenchus penetrans decreased in both Pasteuria soil treatments (P > 0.03). Population densities of Pratylenchus were not significantly different among soils with and without Pasteuria at the two-week harvest period (P > 0.17). At the 8-week harvest, lesion nematode population densities were significantly lower in soils with Pasteuria than in soils without Pasteuria $(\mathrm{P}=0.09)$. Results suggest that reproduction of Pratylenchus penetrans on Phaseolus vulgaris cv. Jade is lower in soils with Pasteuria detected on lesion nematodes than in soils without Pasteuria detected on Pratylenchus. 


\section{Dedication}

This work is dedicated to the memory of several family members, and especially to my dear friend Meredith Ann Thompson of Annandale, Virginia. Meredith was a fellow scientist, environmentalist, and nature aficionado. She would have been proud of this work and the lessons I learned. To my grandparents, John Robert King and Lois Virginia Woods King of Marion, Virginia, who brought unconditional love and patience to our family's table. To my greatgrandmothers, Nannie Mae Reeves King, who modeled happiness as a choice, and Louise Virginia Thomas Woods, who taught me how to give loving hugs and pick a good switch off of a Forsythia bush. To my brother and sister, Mikal Wayne Deel, who made everyone near him feel loved, and Aimee Michelle Fisher, who was always an angel.

This work is also dedicated to all of my TIRELESS cheerleaders: family, friends, and colleagues; and especially to CE who showed me compassion, patience, and grace. To my siblings, Tiffany Leigh King-Hash, Robb Fisher, and Jenny Workman-Fisher. To my father, Michael Joseph Barrett, who teaches me to be kind and to value others based on their character. Most of all, this work is dedicated to my mother, Tonda Gail King-Barrett, for teaching me to be independent and introspective, and for being the greatest advocate of my efforts to live my dreams with passion and tenacity. 
Acknowledgments

Financial support for this research was provided by the Organic Farming Research Foundation; The West Virginia University Davis College of Agriculture, Natural Resources and Design; and the USDA Hatch project NE-1040. Cultures of Pratylenchus penetrans were generously provided by the Nematology Laboratory at USDA-ARS Beltsville, MD. Soil analyses were conducted by the WVU Soil Chemistry Research Laboratory and the WVU Soil Testing Laboratory.

I pay deepest gratitude to my graduate advisor, Dr. James B. Kotcon, for his assistance, guidance and endless patience throughout this endeavor. His fervor and respect for science are unmatched and he has an unwavering ability to be positive and supportive at all times.

I sincerely appreciate the guidance, support, and feedback provided by my advisory committee members: Dr. Louis McDonald, Dr. Joseph Morton, and Dr. Alan Sexstone. Based on their unique areas of expertise, their recommendations provided me with a stronger foundation and a broader perspective for this research.

This work could not have been completed without the help of Joshua S. LaValle, Caroline A. Copenhaver, Angel Sampson, Evan Anderson, and Michelle Apolaro, all of whom reviewed sections of this report. Special thanks to Joshua and Caroline for their assistance with organizing the survey of organic farm soils, collecting and processing soil samples, and harvesting experiments.

I am thankful for the farm managers and growers who kindly participated in the survey of certified organic farms. It was a pleasure visiting your farms and getting to know you.

Additionally, I would like to thank and recognize the following individuals: Dr. Barton Baker for granting a teaching assistantship and extended funding during my tenure at WVU. Drs. 
Gary K. Bissonnette and Barton Baker for funding to attend a Nematode-Bacteria Symbioses Workshop hosted by the University of Arizona. Dr. Daniel Panaccione for his support in preparation for seminar presentations and for inspiring my lifelong adoration of Mycology. Dr. William Bryan for his guidance during my teaching assistantship and many hours of engaging dialogue. Drs. Gary K. Bissonnette, William MacDonald, Mannon Gallegly, and Yong-Lak Park for enlightenment and entertainment during pastime conversations. I am also grateful to every member of the WVU faculty and staff for all they do to provide a positive and memorable experience for every student.

Finally, I would like to say thank you to every person who remained patient and supportive of me during this project. 


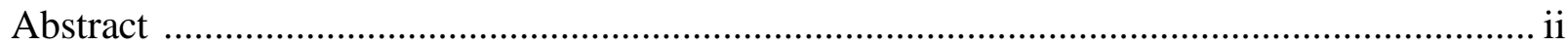

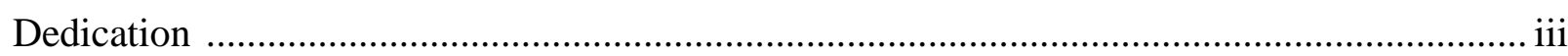

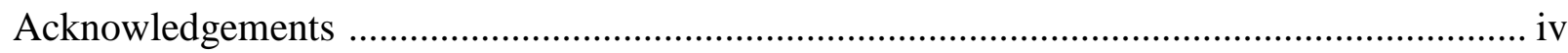

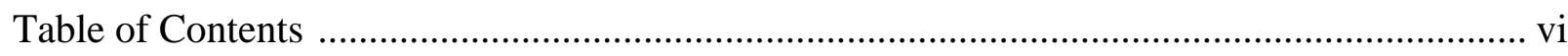

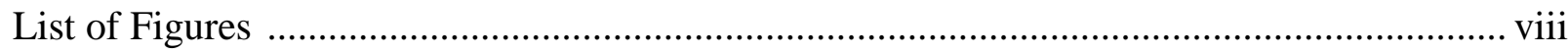

List of Tables

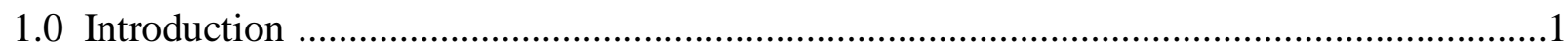

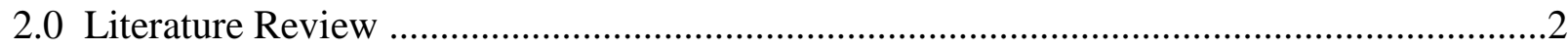

2.1 Biology of Pasteuria Metchnikoff ................................................................2

2.2 Biology of Pratylenchus Filipjev ..............................................................20

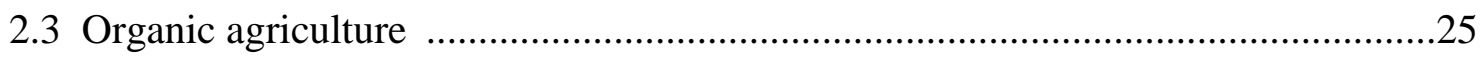

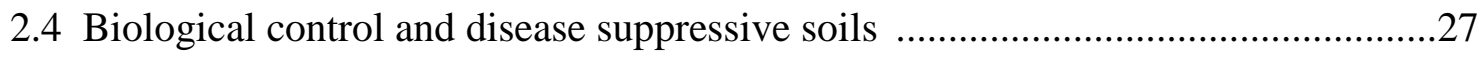

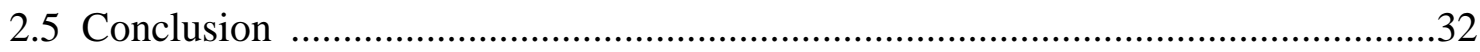

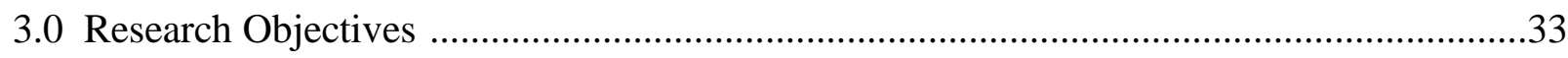

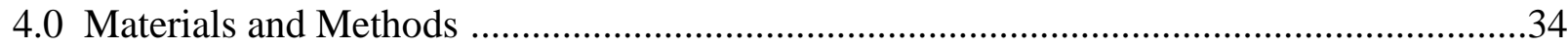

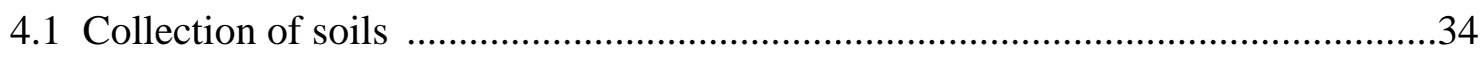

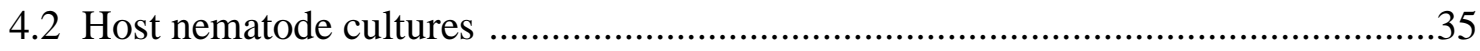

4.3 Experimental design and preparation of treatments ......................................

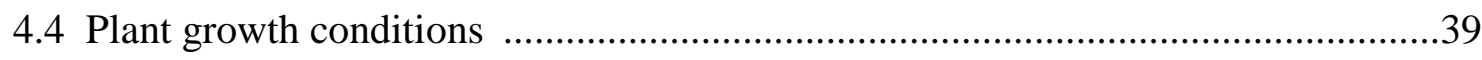

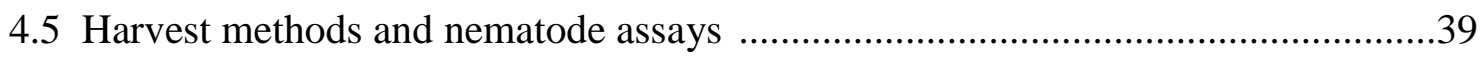

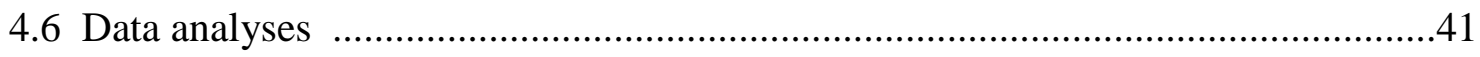


5.0 Results

5.1 Survey of Pasteuria on lesion nematodes in certified organic cropping soils ........42

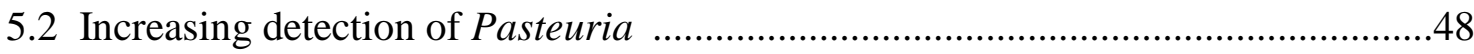

5.3 Reproduction of Pr. penetrans in four soil treatments ....................................48

5.4 Reproduction of Pr. penetrans in soils with and without Pasteuria .....................50

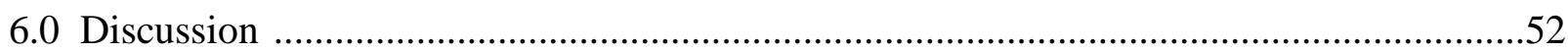

6.1 Survey of Pasteuria on lesion nematodes in certified organic cropping soils ........52

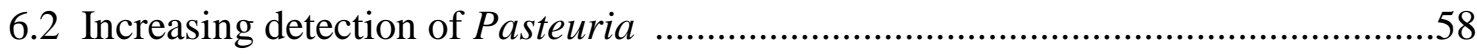

6.3 Reproduction of Pr. penetrans in four soil treatments .....................................59

6.4 Reproduction of Pr. penetrans in soils with and without Pasteuria ....................61

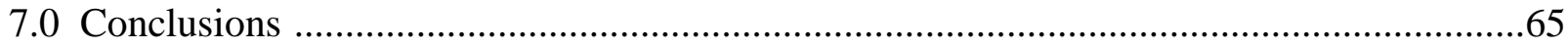

8.0 Appendix A: Host crop history for soils collected from certified organic farms in the

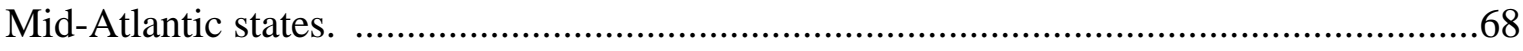

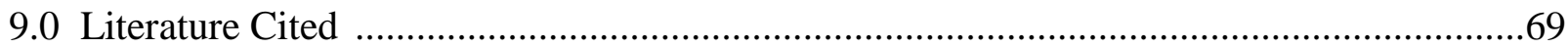


Figure 5.1. Distribution of Pratylenchus and Pasteuria on Pratylenchus in soils collected from certified organic farms in Maryland, Ohio, Pennsylvania, Virginia, and West Virginia.

Figure 5.2. Frequency of Pratylenchus nematodes recovered from $100-\mathrm{cm}^{3}$ soil

for 34 samples collected from certified organic farms in the Mid-Atlantic states.

Figure 5.3. Means and standard error for the total number of Pratylenchus

nematodes per 1-gram root from green bean (Phaseolus vulgaris) cv. Jade in four

soil treatments.

Figure 5.4. The mean number of lesion nematodes recovered at 2 and 8 weeks after inoculation in soil treatments with or without Pasteuria endospores. 
Table 4.1. Fifteen counties from five Mid-Atlantic states represented in the survey of Pasteuria on Pratylenchus from certified organic cropping soils.

Table 4.2. Soil pH, soil type, soil texture, and organic matter content (percent carbon and nitrogen) of six soil pairs used in an experiment to compare reproduction of Pratylenchus penetrans on Phaseolus vulgaris in soils with and without Pasteuria.

Table 5.1. Frequency of Pasteuria endospores attached to Pratylenchus recovered

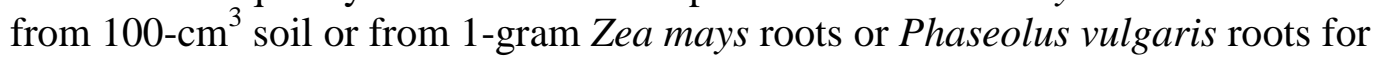
six samples collected from certified organic farms in the Mid-Atlantic states.

Table 5.2. Proportion of Pratylenchus with and without Pasteuria recovered from $100-\mathrm{cm}^{3}$ soil or from 1-gram Zea mays roots or Phaseolus vulgaris roots for six samples collected from certified organic farms in the Mid-Atlantic states.

Table 5.3. Mean population density of Pratylenchus recovered from certified organic farm soils in the Mid-Atlantic states.

Table 5.4. Correlation coefficients of soil parameters measured for 16 of 22 samples in which Pratylenchus was detected in a survey of organic soils from five Mid-Atlantic states. Pasteuria was not detected on Pratylenchus in these samples.

Table 5.5. Correlation coefficients of soil parameters measured for 6 of 22 samples in which Pasteuria was detected on Pratylenchus in a survey of organic soils from five Mid-Atlantic states.

Table 5.6. Paired contrasts of mean number of lesion nematodes recovered from 1-gram root from green bean (Phaseolus vulgaris) cv. Jade in four soil treatments.

Table 5.7. Analysis of variance of treatment effects on the number of lesion nematodes recovered per plant from different soil types with and without Pasteuria endospores.

Table 5.8. Paired contrasts of mean number of lesion nematodes recovered from soils at 2 and 8 weeks after inoculation in soil treatments with or without Pasteuria endospores.

Table 5.9. Analysis of variance of treatment effects of soil $\mathrm{pH}$ on the number of lesion nematodes recovered from soils with and without Pasteuria endospores. 


\subsection{INTRODUCTION}

Root-lesion nematode species in the genus Pratylenchus Filipjev are pathogenic to a wide variety of agricultural crops. Pratylenchus penetrans (Cobb) Filipjev and Shuurmans-Stekhoven is a particularly virulent species known to reduce crop yields and cause significant economic losses. Pest management options for lesion nematodes are limited, especially for organic crop production, which relies mainly on agricultural management practices and biological pest control. Several members of genus Pasteuria Metchnikoff are naturally occurring bacteria that parasitize plant-parasitic nematodes. In the United States, formulations of Pasteuria species are used to control populations of root-knot nematodes (Meloidogyne spp.) and soybean cyst nematodes (Heterodera glycines). There are currently no commercially available formulations of Pasteuria to treat soils infested with Pratylenchus penetrans.

New isolates of Pasteuria are obtained from infected nematodes recovered from soils collected for nematode surveys. Few observations of lesion nematodes infected by Pasteuria have been reported (Chen and Dickson, 1998; Gonzaga and Santos, 2009). The geographic distribution and frequency of Pasteuria and Pratylenchus species occurring in organic cropping soils in the Mid-Atlantic United States currently is not known. Pasteuria endospores were observed on Pratylenchus from vegetable plot soils at the West Virginia University Organic Research Farm (J. Kotcon, pers. commun.). Lesion nematode populations fail to increase in the presence of suitable host crops and the source of nematode suppression in these soils has not been investigated. Interactions of Pasteuria and lesion nematodes in organically managed soils have yet to be measured.

The objective for this study was to increase the understanding of interactions between Pasteuria and Pratylenchus penetrans and to determine the role Pasteuria species may have as a 
biological control agent of lesion nematode populations in agricultural crop production systems. Therefore, a survey was conducted to establish the occurrence of Pasteuria on lesion nematodes in certified organic soils collected from Maryland, Ohio, Pennsylvania, Virginia, and West Virginia. Soil samples collected for this survey that met specific criteria were planted with corn (Zea mays) and green bean (Phaseolus vulgaris) to increase detection of Pasteuria on the natural lesion nematode populations in these soils.

Experiments were conducted to determine effects of Pasteuria on reproduction of Pr. penetrans on green bean (Phaseolus vulgaris) cv. Jade in certified organic soils. One experiment was designed to investigate the source of nematode suppression in WVU Organic Research Farm soils and evaluate effects of soil volume on reproduction of Pr. penetrans on green bean. Twelve of the soils collected during the survey of certified organic farms were used in another experiment that compared reproduction of Pr. penetrans in soils with and without Pasteuria.

\subsection{LITERATURE REVIEW}

\subsection{Biology of Pasteuria Metchnikoff, 1888}

Members of genus Pasteuria are gram-positive, endospore-forming, obligate parasites of cladocerans and nematodes. Isolates of Pasteuria are associated with more than 300 species of nematodes, and many isolates are reported to suppress populations of plant-parasitic nematodes in cropped soils (Chen and Dickson, 1998). Investigations of the biological control potential of these naturally occurring nematode antagonists are underway globally.

\subsubsection{Taxonomy}

In 1888, Metchnikoff described Pasteuria ramosa as a parasite of water fleas, Daphnia spp. (Ebert et al., 1996). In 1906, Cobb observed the nematode Dorylaimus bulbiferous infected with refractile endospores and suggested the parasite was a sporozoan. When Thorne observed 
similar endospores on Pratylenchus brachyurus in 1940, he classified it as Duboscqia penetrans (Sayre et al., 1988). Several decades later, scanning electron micrographs of D. penetrans revealed morphological characteristics similar to that of Bacillus species and it was renamed Bacillus penetrans (Mankau, 1975). Sayre and Starr (1985) reported definitive evidence that B. penetrans was distinctly dissimilar from members of genus Bacillus and more closely resembled the cladoceran parasite Pasteuria ramosa as originally described by Metchnikoff. They suggested that B. penetrans was related to Pa. ramosa and proposed the name Pasteuria penetrans (Thorne) to replace B. penetrans Mankau 1975.

Similarities in the ultrastructure and development of Pasteuria species and 16S rRNA sequence data indicate nematode-parasitic Pasteuria species and Pa. ramosa are closely related, which supports grouping of these organisms in the same genus (Mankau and Imbriani, 1975; Sayre et al., 1979, 1983, 1991a, 1991b; Sayre and Starr, 1985; Starr and Sayre, 1988; Sturhan et al., 1994, 2005; Anderson et al., 1999; Bekal et al., 2001; Giblin-Davis et al., 2001, 2011; Preston et al., 2003; Atibalentja et al., 2000, 2004a, 2004b; Charles et al., 2005; Schmidt et al., 2008, 2010). In 2009, the genus Pasteuria was removed from Family Alicyclobacillaceae and reclassified into Family Pasteuriaceae, Order Bacillales (Fritze, 2004; Garrity et al., 2005; Dickson et al., 2009).

With regard to early scientific literature, Duboscqia penetrans, Bacillus penetrans, and Pasteuria penetrans may refer to isolates or species of nematode-parasitic Pasteuria and are accurately referred to as Pasteuria species, or as "members of the Pasteuria penetrans group" (Sayre and Starr, 1985; Sayre et al., 1991b; Chen and Dickson, 1998). Some Pasteuria species referred to as Pasteuria penetrans may represent another isolate that has since been reclassified. 
Pa. penetrans is accepted as the species that is primarily parasitic on members of Meloidogyne and Pa. penetrans sensu stricto are parasites of Meloidogyne incognita (Starr and Sayre, 1988).

\subsubsection{Pasteuria species diversity}

Pasteuria species have been traditionally distinguished by host preference, life cycle, and morphology of vegetative structures. The type species Pasteuria ramosa Metchnikoff 1888 is a parasite of water fleas (Cladocera; Daphinidae) (Sayre et al., 1979; Ebert et al., 1996). Metchnikoff observed Pa. ramosa on Daphnia pulex Leydig and D. magna Strauss. In the century following Metchnikoff's report, researchers described a variety of cladoceran parasites similar to Pa. ramosa and debated the taxonomic classification of these organisms (Sayre et al., 1983). Sayre and Wergin (1977) and Sayre et al. (1983) compared ultrastructure and morphology of Pa. ramosa and the nematode-parasitic species "Bacillus penetrans" Mankau. These authors reviewed the taxonomic history of Pa. ramosa and clarified classification of the organism as the parasite of cladocerans originally described by Metchnikoff.

Most known isolates of Pasteuria are parasites of nematodes. Pasteuria penetrans parasitize Meloidogyne, Pa.thornei are parasites of Pratylenchus, and Pa.nishizawae are parasites of Heterodera and Globodera (Sayre and Starr, 1985; Starr and Sayre, 1988; Sayre et

al., 1991a, 1991b). Candidatus species include Pasteuria usgae on Belonolaimus longicaudatus, Pa. hartismeri on Meloidogyne ardenensis, and Pa. aldrichii on Bursilla (Giblin-Davis et al., 2003, 2011; Bishop et al., 2007). Sturhan et al. (1994), Orajay (2009), and Schmidt et al. (2010) describe isolates of Pasteuria species infecting Heterodera goettingiana, Mesocriconema ornatum, and Rotylenchulus reniformis.

Chen and Dickson (1998) stated that while most reports of Pasteuria-like organisms are based on observation of endospore attachment, this does not confirm infection of the nematode 
host. Host specificity and endospore attachment reflect "host preference." A few Pasteuria species infect multiple nematode genera; however, most species have a narrow host range and this host preference is used, in part, to categorize isolates of Pasteuria.

\subsubsection{Life cycle and mode of infection}

Pasteuria are pleomorphic and varying descriptions of the life cycle, ultrastructure, and morphology of nematode-parasitic Pasteuria species have been reported (Mankau, 1975;

Mankau and Imbriani, 1975; Imbriani and Mankau, 1977; Mankau and Prasad, 1977; Sayre and Wergin, 1977; Sayre and Starr, 1985, 1988; Sayre et al., 1979, 1983, 1988, 1991a, 1991b; Starr and Sayre, 1988; Sturhan et al., 1994, 2005; Chen et al.,1997; Serracin et al. 1997; Chen and Dickson, 1998; Giblin-Davis et al., 2001, 2011; Preston et al., 2003; Atibalentja et al., 2004a; Davies, 2009; Schmidt et al., 2010; Davies et al., 2011). The majority of these reports were summarized by Dickson et al. (2009).

The host-parasite interactions of Meloidogyne and Pasteuria penetrans have been studied extensively and are the model used to describe the life cycle and development of Pasteuria on plant-parasitic nematodes (Dickson et al., 2009). Davies et al. (2011) proposed amendments to the life cycle based on electron micrographs of Pasteuria-infected Meloidogyne females and juveniles. Authors described three phases of the cycle: Phase I, attachment and germination;

Phase II, rhizoid formation and exponential growth; and Phase III, sporogenesis. Proliferation of Pasteuria throughout the nematode body eventually disrupts metabolic processes and results in nematode death.

During Phase I, root-knot nematode larvae (J2) move through soil where mature Pasteuria endospores attach to the cuticle of the nematode. Collagen-like fibers on the endospore surface may play a role in endospore attachment (Davies, 2009). Although many endospores 
may attach to a nematode, only one is needed for infection to occur. One to 20 endospores have been observed attached to root-knot nematode juveniles. The $\mathrm{J} 2$ enters a plant root and the endospore germinates before the $\mathrm{J} 2$ molts into a third-stage juvenile. Germination occurs within 4 to 12 days after a root-knot nematode $\mathrm{J} 2$ establishes a feeding site in a host root (Sayre and Wergin, 1977; Davies et al., 1988). Germination begins when a germ tube emerges from the endospore core and penetrates the cuticle and hypodermis of the nematode body. Mankau and Imbriani (1975) and Mankau et al. (1976) suggested enzymes aid in germination. Davies et al. (1990) observed mature Pasteuria endospores in root-knot nematode J2s and suggested that establishment of a feeding site is not required for germination to occur.

Phase II begins when the germ tube differentiates into either a filamentous, rhizoid-like structure or microcolonies of rod-shaped structures that appear to be similar to Bacillus cells. The rhizoid-like structure grows into the pseudocoelom until filamentous growth discontinues, and then microcolonies develop. When filamentous growth does not occur, the microcolonies develop inside the body cavity at the site of penetration. The rod-shaped cells reproduce quickly and form tight clusters that have a granular appearance during this period of exponential growth. Rod-shaped cells were observed by Mankau (1975) in M. javanica infected by Pa. penetrans; however, these structures were not verified to be cells of Pasteuria.

In Phase III, there is a transition from exponential to stationary growth and sporogenesis occurs. The rod-shaped cells thicken and form thalloid-like chains that break apart from the granular masses. Cytoplasmic changes occur within each cell as it develops into an ovate sporangium. A membrane develops inside the sporangium, and the upper part of the cell — the forespore - is separated from the lower parasporal section. The cytoplasm within the forespore contracts into an electron-opaque structure that becomes the endospore. In the parasporal section, 
fibers form around the outer wall of the endospore, and a loose outer membrane — the exosporium - develops around these parasporal fibers. The remaining portion of the paraspore degenerates and each sporangium encloses a single mature endospore. Sporangia fill the nematode body cavity and endospores are released into the soil when the nematode cadaver degrades.

Previous reports of the life cycle, ultrastructure, and morphological characteristics of $\mathrm{Pa}$. penetrans and other Pasteuria species differ from Davies et al. (2011). Serracin et al. (1997) described five stages of $\mathrm{Pa}$. penetrans development in $M$. arenaria: (i) endospore germination, (ii) vegetative growth, (iii) thalli differentiation, (iv) sporulation, and (v) maturity of endospores. Authors presented photographs of structures observed with light microscopy that were verified by scanning electron microscopy. Endospore attachment and germination, as well as final stages of endospore formation, are similar to that of Davies et al. (2011). However, developmental stages between germination and sporulation were described as mycelial and not bacterial. Similar descriptions of $\mathrm{Pa}$. penetrans have been presented by other authors that were previously noted in this section.

After endospore germination, the germ peg develops into dichotomously branched, septate mycelia that contain hyphal cells. Septate hyphal cells have a compound cell wall with inner and outer membranes, and septa are formed by the inner membrane. Lysis of intercalary cells forms daughter colonies of mycelia that are passively transported throughout the nematode body. Sporulation begins when distal cells of the hyphae bifurcate, swell into ovate cells, and develop into ovate sporangia that lyse from parent hyphae. Hyphae cease growth and eventually disintegrate. Observations of concurrent vegetative growth and sporulation in $M$. javanica have been reported (Mankau and Imbriani, 1975). 
Mycelial vegetative growth was also reported for Pasteuria on Pratylenchus, Heterodera, Belonolaimus, Anaplectus, Plectus, and Bursilla by Sayre et al. (1988, 1991a, 1991b), Starr and Sayre (1988), Sturhan et al. (1994, 2005), Giblin-Davis et al. (2001, 2011), and Atibalentja et al. (2004a). Dickson et al. (2009) indicated this mycelial-like development is only observed in species of Pasteuria and Thermoactinomyces. Future reports of the Pasteuria life cycle may propose amendments that include the stages described by Davies et al. (2011).

While Pasteuria infection can occur in all life stages of vermiform and sedentary nematodes, no infection has been reported in eggs. Infected juveniles have been observed in several nematode species and nematode feeding is not required for endospore germination to occur (Chen and Dickson, 1998; Bird et al., 2003; Davies, 2009; Hewlett et al., 2010; Schmidt et al., 2010; Davies et al., 2011). Factors that affect endospore attachment and germination include species of Pasteuria, species of host nematode, soil texture, temperature, moisture, and $\mathrm{pH}$

(Serracin et al., 1997; Chen and Dickson, 1998; Mateille et al., 2002; Dabiré and Mateille, 2004).

\subsubsection{Sporangia and endospores}

The morphology of Pasteuria endospores differs from that of other endospore-forming bacteria. Pasteuria has two morphological types of endospores. One form is enclosed in a loose membrane called the exosporium. The other form is missing the exosporium and has two recognizable parts: (i) a central, round endospore encased by (ii) a material referred to as the "peripheral matrix" or "perisporium" (Dickson et al., 2009). This peripheral matrix is made up of microfibrillar strands called parasporal fibers. These fibers, which are approximately $1.5 \mathrm{~nm}$ thick, spread out and down the sides of the endospore toward the nematode cuticle. Endospore morphometrics are difficult to assess due to the amorphous nature of the parasporal fibers. 
The morphology of sporangia and endospores varies within and between isolates of Pasteuria. The cladoceran parasite, Pa. ramosa, has teardrop-shaped sporangia that are 3.3 to 4.1 $\mu \mathrm{m}$ in diameter and 4.8 to $5.7 \mu \mathrm{m}$ in height, and endospore diameter ranges from 2.1 to $2.4 \mu \mathrm{m}$ (Starr and Sayre, 1988; Sayre et al. 1991b). Sayre et al. (1991b) determined sporangia and endospore morphometrics for Pa. penetrans, $\mathrm{Pa}$. nishizawae, and $\mathrm{Pa}$. thornei with light microscopy. Pa. penetrans sporangia are $4.5 \pm 0.3 \mu \mathrm{m} X 3.6 \pm 0.3 \mu \mathrm{m}$ (diameter and height), and endospores are $2.1 \pm 0.2 \times 1.7 \pm 0.2 \mu \mathrm{m}$. Sporangia of $P a$. nishizawae are $5.3 \pm 0.3 \mu \mathrm{m} \times 4.3 \pm$ $0.3 \mu \mathrm{m}$ and endospores are $2.1 \pm 0.2 \times 1.7 \pm 0.1 \mu \mathrm{m}$. Pa. thornei sporangia are rhomboid-shaped with a diameter of $3.5 \pm 0.2 \mu \mathrm{m}$ and height of $3.1 \pm 0.2 \mu \mathrm{m}$, and endospores are $1.6 \pm 0.1 \mu \mathrm{m} X$ $1.5 \pm 0.1 \mu \mathrm{m}$. Sporangia of Pa. penetrans and Pa. nishizawae are cup-shaped.

Giblin-Davis et al. (1990) described spores from several plant-parasitic nematodes in Bermudagrass. They reported small and large endospore isolates of Pasteuria on Hoplolaimus galeatus, with sporangia diameter ranging from 3.19 to $4.64 \mu \mathrm{m}$ and width of endospores ranging from 1.45 to $2.45 \mu \mathrm{m}$ for the small endospore isolate, versus 6.53 to $8.05 \mu \mathrm{m}$ and 2.72 to $3.54 \mu \mathrm{m}$, respectively, for the large endospore isolate. For Pasteuria observed on Belonolaimus longicaudatus, sporangia diameter ranged from 4.71 to $7.00 \mu \mathrm{m}$ and endospore width varied from 2.33 to $3.78 \mu \mathrm{m}$. Sporangia for Pasteuria observed on Tylenchorhynchus annulatus were 3.98 to $5.38 \mu \mathrm{m}$ in diameter and width of endospores was 2.21 to $2.95 \mu \mathrm{m}$. The diameter of sporangia for Pasteuria on Helicotylenchus microlobus was 2.78 to $4.73 \mu \mathrm{m}$ and endospore width was 1.39 to $2.50 \mu \mathrm{m}$. For Pa. penetrans observed on Meloidogyne juveniles, sporangia ranged from 2.91 to $4.19 \mu \mathrm{m}$ in diameter and endospore width was 1.22 to $1.98 \mu \mathrm{m}$.

An adult root-knot nematode female infected with $\mathrm{Pa}$. penetrans may be filled with $2 \mathrm{X}$ $10^{6}$ endospores (Sayre et al., 1991b; Dickson et al., 2009). Sayre et al. (1991b) stated that the 
number of sporangia in Meloidogyne females was four times that of Heterodera females and also reported "a few hundred sporangia" present in lesion nematode cadavers. Atibalentja et al. (1998) reported $3 \times 10^{5}$ endospores from Heterodera glycines females infected with an isolate of Pasteuria from Illinois. Giblin-Davis et al. (2001) reported the average number of endospores recovered from B. longicaudatus cadavers was 1,483 $\pm 1,199$ for females, 3,633 $\pm 3,095$ for males, and 4,700 $\pm 1,972$ for juveniles.

Pasteuria endospores are resistant to heat, desiccation, and some nematicides (Stirling et al., 1986; Chen and Dickson, 1998; Bekal et al., 2000; Freitas et al., 2000; Kariuki and Dickson, 2007). Bekal et al. (2000) reported that Pa. penetrans endospores in a soil sample that had been dried and stored for 21 years were infective to $M$. incognita. Juveniles were inoculated into moistened soil, and endospore-attached nematodes were recovered. M. incognita were cultured on tomato at $26^{\circ} \mathrm{C}$ in this soil, and infected female nematodes were observed after 8 weeks.

Attachment of Pa. penetrans endospores to Meloidogyne juveniles in soil is affected by nematode motility in soil, as well as soil temperature and moisture (Brown and Smart, 1984; Stirling et al., 1986; Oostendorp et al. 1990; Hatz and Dickson, 1992). Brown and Smart (1984) observed significantly higher proportions of $M$. incognita juveniles attached with Pa. penetrans endospores from soils that were moistened 3 days prior to nematode inoculation compared to soils moistened the day of inoculation ( $\mathrm{P}<0.001)$. Stirling et al. (1990) reported that attachment of $P$ a. penetrans endospores to $M$. javanica juveniles was higher at $27^{\circ} \mathrm{C}$ than at $18^{\circ} \mathrm{C}$.

\subsubsection{Use of Pasteuria for biological control of plant-parasitic nematodes}

The study of Pasteuria as biological control agents of plant-parasitic nematodes is timeintensive and laborious. Initial efforts to produce in vitro cultures of Pa. penetrans were thwarted by obligate parasitism and strict host specificity. Therefore, researchers developed various in 
vivo methods to culture Pa. penetrans on host nematodes, but these methods are not practical for commercial-scale production (Mankau, 1975; Mankau and Prasad, 1977; Dutky and Sayre, 1978; Stirling and Wachtel, 1980; Sharma and Stirling, 1991; Hewlett and Dickson, 1993; Chen et al., 1996a, 1996b; Hewlett et al., 2004).

\subsubsection{Methods of endospore inocula production}

Mankau (1975) and Mankau and Prasad (1977) propagated endospore-infested soils from a naturally occurring background population of Pa. penetrans discovered in $M$. javanica pot cultures. This population of M. javanica and Pa. penetrans had been collected from fields near Riverside, CA. Infected Meloidogyne populations were replanted with tomato seedlings and inoculated with healthy juveniles at 6-month intervals. The amount of endospore inoculum was not determined. Instead, soil samples were assayed to determine the level of observed infection.

When at least 50\% of Meloidogyne J2s inoculated in a sample became infected after exposure to the soil, it was considered an endospore-infested soil. These soils were periodically air-dried at 25 to $30^{\circ} \mathrm{C}$ and then stored for future use.

Methods for in vivo endospore production were optimized by Stirling and Wachtel (1980) and by Sharma and Stirling (1991), among others. Infected M. javanica females were dissected from tomato roots and crushed in water; then concentrations of Pa. penetrans endospores were determined with a hemacytometer. Stirling and Wachtel (1980) reported one to ten endospores attached to M. javanica juveniles that soaked in a suspension of 500,000 to 3,000,000 Pa. penetrans endospores/mL for 24 hours. Endospore-encumbered juveniles were inoculated on tomato in greenhouse pot culture $\left(5,000 \mathrm{~J} 2\right.$ per plant). After 8 weeks at $27^{\circ} \mathrm{C}$, tomato roots were harvested and dried, then pulverized until the material passed through a 710- $\mu \mathrm{m}$-pore sieve. This root material was either combined with soil or used to prepare liquid 
endospore suspensions. Both endospore formulations were used to conduct attachment assays and to amplify $\mathrm{Pa}$. penetrans in greenhouse pot culture.

In one assay, the percent of endospore-attached juveniles recovered 24 hours after inoculation into endospore-infested soil was $39 \%, 45 \%, 85 \%$, and $99 \%$ for $10,40,70$, and $100 \mathrm{mg}$ root material per kg soil, respectively. Juveniles had one to six endospores attached. In another assay, a suspension containing 0.2 grams of endospore-infested material was ground with a mortar and pestle and root debris was removed with a $25-\mu \mathrm{m}$-pore sieve. Juvenile nematodes agitated in $100 \mathrm{~mL}$ of this endospore suspension using an aquatic air bubbling system had endospores attached after 5 hours.

Sharma and Stirling (1991) compared production of Pa. penetrans endospores on $M$. javanica grown on tomato (Solanum lycopersicum cv. Floradade or cv. Tiny Tim) in two types of planting containers. Tomato seedlings in 15-cm-diameter pots were inoculated with 5,000 J2s and seedlings in 34 X $28 \times$ 4.5-cm trays were inoculated with 100,000 J2s. Juveniles had 5 to 20 endospores attached at the time of inoculation. Plants were grown in a greenhouse at 20 to $30^{\circ} \mathrm{C}$ and harvested 60 to 90 days after nematodes were inoculated. Roots were shaken to remove sand, then air-dried and milled into a powder. The material was soaked in an enzyme solution for 3 hours, then ground in a mortar and pestle for 5 minutes. The suspension was diluted with water and endospores were quantified with a hemacytometer. The amount of endospore-filled tomato root material produced in the trays was five times greater than in the pots. Ten to 24 grams of tomato root material collected from trays contained 10-120 X $10^{8}$ endospores. In their study, the primary factors that affected endospore production were plant species, density of nematode inoculum and time of harvest. 
These methods of producing dry and liquid forms of in vivo-produced $\mathrm{Pa}$. penetrans endospores enabled further laboratory and field studies of Pasteuria on Meloidogyne. After reliable means of producing in vivo inocula were developed, research focused on increasing the amount of endospore inocula, improving endospore quantification, and reducing the amount of time needed to conduct experiments.

Using methods described above to produce $\mathrm{Pa}$. penetrans isolate $\mathrm{P}-100$ root powder inoculum, Hewlett and Dickson (1993) developed a centrifugation endospore attachment procedure. A $200-\mu \mathrm{L}$ suspension of endospores and $M$. javanica $\mathrm{J} 2$ s were combined in a $250-\mu \mathrm{L}$ microfuge tube and centrifuged at $9,500 \mathrm{~g}$ for 2 minutes. At 1,000 endospores $/ 200 \mathrm{~J} 2,61 \%$ of juveniles had 0.5 to 1.5 endospores/nematode attached. At 10,000 and 100,000 endospores/200 $\mathrm{J} 2,100 \%$ of juveniles had 4.4 to 7.7 attached endospores/J2 and 21.8 to 37.2 attached endospores/J2, respectively. This method decreased the amount of time needed to conduct endospore attachment assays.

Pasteuria endospores may be difficult to distinguish from Bacillus endospores, fungal spores and particles of debris in suspension. Chen et al. (1996a) questioned early assessments of endospore concentrations. These authors compared six endospore quantification methods and reported highest precision and accuracy with mortar disruption and machine disruption. Pa. penetrans isolate P-20 was propagated on M. arenaria race 1 grown on tomato (Solanum lycopersicum cv. Rutgers) in greenhouse pot culture. Endospore-infested root material was milled until it passed through a 5-mm-pore sieve. For mortar disruption, a 0.5-gram subsample was mixed with $5 \mathrm{~mL}$ deionized water, ground with a mortar and pestle, and then diluted up to $100 \mathrm{~mL}$ in an Erlenmeyer flask. For machine disruption, roots were milled until the material passed through a $250-\mu \mathrm{m}$-pore sieve and a 0.5 -gram subsample was mixed into $100 \mathrm{~mL}$ 
deionized water. Endospore concentrations were 83.7 million and 79 million endospores per gram of root for mortar disruption and machine disruption, respectively. The least amount of debris was observed in suspensions prepared by machine disruption, and this method allowed for precise and accurate assessment of endospore concentrations.

Continued development and modifications of these methods support investigations of Pasteuria as a biological control for root knot nematodes in field and laboratory assays.

Researchers are interested in finding Pasteuria isolates that parasitize multiple nematode hosts. Many host range studies have been conducted, as have studies of disease suppressive soils in which Pasteuria has been observed on nematodes of interest.

\subsubsection{Suppression of Meloidogyne by Pasteuria}

The potential use of Pasteuria penetrans for biological control of Meloidogyne has been investigated by several authors. Some studies induced suppression of root-knot nematodes by incorporating in vivo-produced endospore inocula, and others compared treatments of soils observed to be naturally suppressive to root-knot nematodes. Suppression of Meloidogyne arenaria, M. incognita and $M$. javanica by Pa. penetrans has been reported for several field soils (Oostendorp et al., 1991a; Chen et al., 1994; Chen et al., 1996b; Weibelzahl-Fulton et al., 1996; Freitas et al., 2000; Cetintas and Dickson, 2004; Kariuki and Dickson, 2007).

Oostendorp et al. (1991a) conducted a 2-year field microplot experiment to determine effects of Pa. penetrans isolate P-20 on infection of $M$. arenaria and peanut yield. There were three treatments: (i) M. arenaria and Pa. penetrans present, (ii) M. arenaria only, and (iii) untreated control. Pa. penetrans isolate P-20 was originally collected from $M$. arenaria race 1 found in a peanut field naturally infested with Pasteuria in Levy County, Florida. Greenhouse cultures of this isolate were maintained on M. arenaria race 1 on tomato (Lycopersicon 
esculentum Mill. cv. Rutgers). Endospore-filled M. arenaria females were dissected from infected peanut hulls and crushed in water. Juveniles were incubated in the suspension on a shaker and after 3 hours, $80 \%$ of the $\mathrm{J} 2$ s had one or more endospores attached. Sixty tomato plants were each inoculated with 1,000 J2s, with 30 of the plants receiving endospore-attached juveniles. Thirty tomato plants for the untreated control were not inoculated. Plants grew for 85 days before roots were harvested and mixed with corresponding soil. The tomato root and soil inocula were transferred to the microplots and peanuts were direct seeded into each plot in late spring each year.

Peanut yields from the untreated control plots were significantly higher than other treatments over all seasons. After two growing seasons, peanut yields were significantly higher in treatments with $\mathrm{Pa}$. penetrans on $\mathrm{M}$. arenaria than in treatments with $M$. arenaria alone $(\mathrm{P} \leq 0.05)$. Initial and final data indicated the percent of juveniles recovered from $P a$. penetrans treatments that had one to four endospores attached increased from $7 \%$ to $28 \%$, and juveniles with five or more endospores attached increased from zero to $41.6 \%$. This study showed that in vivo produced Pasteuria inoculum can increase on host nematodes in field microplots.

Chen et al. (1996b) compared inoculum densities of 0, 1,000, 3,000, 10,000, and 100,000 Pa. penetrans (isolate P-20) endospores per gram soil in a 2-year field study of $M$. arenaria on peanut (Arachis hypgaea). The methods described in the previous section were used to prepare endospore-infested tomato root material. Clay flue liner microplots (25-cm X 40-cm X 100-cm) were imbedded in field soils and populations of $M$. arenaria were introduced and augmented on tomato (Solanum lycopersicum cv. Rutgers). For each microplot, a suspension of endosporeinfested root powder was thoroughly mixed into the top $20-\mathrm{cm}$ of soil and a peanut seedling $(A$. hypgaea cv. Florunner) was planted. Signs and symptoms of root-knot parasitism on peanut were 
significantly reduced at inoculum densities of 10,000 and 100,000 Pa. penetrans endospores per gram soil. At 100,000 endospores per gram soil, peanut yields increased by $94 \%$ and indices for pod and root galls were reduced by $90 \%$ and $81 \%$. The minimum inoculum dose required to suppress M. arenaria on peanut was 10,000 endospores per gram soil.

Chen et al. (1994) noted decreased symptoms of nematode damage in a monocropped tobacco field that contained a mixed population of M. incognita and M. javanica. Pa. penetrans had been reported on Meloidogyne juveniles recovered from these soils. Weibelzahl-Fulton et al. (1996) presented evidence to support the hypothesis that $P a$. penetrans was the cause of rootknot nematode suppression in these soils.

Freitas et al. (2000) compared effects of soil fumigants on Pa. penetrans infecting $M$. arenaria on tomato and tobacco in field and greenhouse trials. Combinations of chloropicrin with 1,3-D or methyl bromide reduced infectivity of $P$ a. penetrans to $M$. arenaria, but metam sodium alone did not inhibit infection. Results also indicated that the naturally occurring suppression of M. arenaria populations in field soils was caused by Pa. penetrans.

Cetintas and Dickson (2004) evaluated suppression of M. arenaria by Pa. penetrans in a monocropped peanut field over a 4-year period. Although percentages of endospore-attached juveniles and infected females recovered from $P a$. penetrans-infested soils were higher than those from control treatments, differences in peanut yields were not significant. M. javanica was discovered in experimental plots and a laboratory assay confirmed that $P a$. penetrans isolate P-20, which is infective to M. arenaria, did not infect $M$. javanica. Infestation of field plots by M. javanica interfered with detection of suppressive effects of $P$ a. penetrans to $M$. arenaria. This explanation was supported by a laboratory assay that eliminated background nematode populations in four field soil treatments: (i) autoclaving, (ii) microwaving, (iii) air-drying, and 
(iv) untreated. Results indicated that $P a$. penetrans endospores were killed by the autoclave treatment and $M$. arenaria was suppressed by $P a$. penetrans in the other three treatments.

Kariuki and Dickson (2007) established a population of Pa. penetrans on M. arenaria at a new field site by incorporating infested plant material into the soil. Okra roots and peanut galls, pods, and roots that were infested with $P$. penetrans were dried and then tilled into the soil. $M$. arenaria-infested plant material was then incorporated into these soils. Peanut and winter wheat were cultivated in soils to augment populations of $\mathrm{Pa}$. penetrans and $\mathrm{M}$. arenaria. At plant harvest, infection of $M$. arenaria by $P a$. penetrans was confirmed based on observations of endospore-attached juveniles and infected females collected from soil and root assays. Field trials conducted at this site confirmed suppression of $M$. arenaria by Pa.penetrans.

\subsubsection{Use of Pasteuria for biocontrol of other nematode species}

Isolates of Pasteuria have been reported for cyst nematodes, Heterodera and Globodera, and some are suppressive to cyst nematode populations (Nishizawa, 1984, 1986, 1987; Davies et al., 1990; Sayre et al., 1991a, 1991b; Noel and Stanger, 1994; Sturhan et al., 1994; Atibalentja et al., 1998, 2000, 2004a; Ma et al., 2005; Noel et al., 2010). Sayre et al. (1991b) compared the morphology and host range of Pasteuria isolates reported by Nishizawa $(1986,1987)$ on Heterodera elachista and H. glycines and defined these isolates as Pasteuria nishizawae. Noel and Stanger (1994) reported a Pasteuria isolate on $H$. glycines recovered from research plots at USDA Urbana, Illinois. The source of this isolate is unknown and authors indicated the morphology of this isolate was not similar to Pa. nishizawae.

Atibalentja et al. (1998) assessed population dynamics of $H$. glycines and its associated Pasteuria isolate originally reported by Noel and Stanger. Analyses of the percentages of juveniles attached with endospores, the numbers of endospores attached per $\mathbf{J} 2$, and nematode 
density indicated that Pasteuria was maintaining nematode populations below the damage threshold. This report indicates that naturally occurring populations of Pasteuria are capable of suppressing $H$. glycines in field soils.

In a 7-year field trial, Noel et al. (2010) established suppression of soybean cyst nematodes by incorporating $\mathrm{Pa}$. nishizawae-infested soil into microplots that were naturally infested with Heterodera glycines. Eight liters of Pa. nishizawae-infested soil were plowed into a 12-m-long row of $H$. glycines-infested soil. Nematode densities were significantly lower in samples that had Pa. nishizawae-infested soil added than in plots without $P$ a. nishizawae $(\mathrm{P} \leq 0.05)$. This study determined that suppression of $H$. glycines by Pa. nishizawae can be transferred.

A few reports of Pasteuria on Pratylenchus indicated infection of Pr. brachyurus and Pr. scribneri by Pa. thornei; however, reports of Pasteuria species suppressing Pr. penetrans are not present in current literature. The first report of Pasteuria observed on a plant-parasitic nematode was Pasteuria thornei on Pratylenchus brachyurus (Thorne, 1940; Sayre et al. 1988). Thorne (1940) described a parasite of Pratylenchus pratensis and classified it as Duboscqia penetrans. When Sayre et al. (1988) studied Thorne's original preserved specimens, they noted that specimens had been relabeled to indicate the host nematode was Pr. brachyurus and not Pr. pratensis.

Starr and Sayre (1988) established Pasteuria thornei as the species of Pasteuria parasitic to root-lesion nematodes and indicated Pratylenchus brachyurus was its primary host. Future taxonomic studies may differentiate isolates that parasitize lesion nematodes other than $P r$. brachyurus. Most studies of Pasteuria on lesion nematodes specify infection of Pr. brachyurus 
and Pr. scribneri (Mankau, 1975; Mankau and Prasad, 1977; Dutky and Sayre, 1978; Bird et al., 2003).

Mankau (1975) compared reproduction of Pr. scribneri on Phaseolus vulgaris in greenhouse pot culture in soils with and without $\mathrm{Pa}$. penetrans. Two soil treatments were prepared. Soil infested with 50 Pr. scribneri per $100 \mathrm{~cm}^{3}$ was mixed in a 1:1 (v/v) ratio with: (1) Pa. penetrans endospore-infested soil and (2) steam-sterilized greenhouse soil. Each soil treatment was divided among five $10-\mathrm{cm}$ pots planted with green beans, which were then grown in a greenhouse. After 55 days, nematodes were recovered from roots and soil and counted with a dissecting microscope. The number of lesion nematodes recovered from endospore-infested soils was $244 \pm 20.3$, compared to $607 \pm 12.7$ recovered from steam-sterilized soils, and differences were significant at $\mathrm{P}=0.01$.

Mankau and Prasad (1977) observed cross-generic parasitism of Pa. penetrans infecting Meloidogyne, Pratylenchus brachyurus and Pr. scribneri, but not Pr. penetrans. Elekçioğlu (1995) reported attachment of Pasteuria endospores to Pratylenchus penetrans but did not observe infection. Other reports of Pasteuria species on Pr. penetrans do not clarify whether or not infection was confirmed (Sayre et al., 1988). Chen and Dickson (1998) reported observations of Pasteuria attached to 12 lesion nematode species from around the world, two of which were Pr. penetrans. Gonzaga and Santos (2009) reported Pasteuria endospore attachment and infection of Pr. brachyurus and Pr. zeae. Information on parasitism of Pratylenchus penetrans by Pasteuria is scarce and studies on interactions between these organisms are lacking.

Pasteuria Bioscience, Inc. in Florida successfully cultured Pasteuria using in vitro fermentation. This company was acquired by Syngenta Crop Protection, LLC in 2012. Econem $^{\mathrm{TM}}$ was the first commercially available formulation of Pasteuria usgae. It was used as a 
biological nematicide to treat the sting nematode, Belonolaimus longicaudatus in turf grass (Pasteuria Bioscience, Inc., 2009, but is no longer in commercial production. Commercial development of additional Pasteuria-based nematicides to control economically important plantparasitic nematodes continues at Syngenta Crop Protection, LLC.

\subsection{Biology of Pratylenchus Filipjev}

The genus Pratylenchus, commonly known as root-lesion nematodes, has been reviewed by Loof (1978), Dropkin (1989), Handoo and Golden (1989), Zunke (1990), Mai et al. (1996), Barker et al. (1998), Shurtleff and Averre (2000), and Castillo and Volvas (2007). Lesion nematodes are 0.45 to $0.70 \mathrm{~mm}$ in length and have a sclerotized stylet that is 15 to $18 \mu \mathrm{m}$ in length. Key morphological features include a broad head with a flattened lip region, large metacorpus, and single ovary. The basal bulb of the esophagus overlaps the intestine lateroventrally.

Members of this genus parasitize a wide range of plants. Select species reduce yields of economically important agricultural and horticultural crops. Plant symptoms of parasitism include visible abrasions on roots, as well as root shedding, increased lateral roots, stunted plant growth, chlorosis, and plant death when parasitism is severe. Lesion nematodes feed on external and internal plant root tissues. After entering a plant host, nematodes migrate within and between cortical cells and consume cell contents, causing cell death and necrotic lesions on the root.

\subsubsection{Life cycle}

All life stages of lesion nematodes overwinter in roots or soil and, except for the egg and first-stage juvenile, are migratory and infective. These nematodes reproduce by parthenogenesis when males are absent or by amphimixis when males are present. Adult females deposit eggs in soil or within plant roots. The first juvenile larva, or $\mathrm{J} 1$, forms within the egg and molts into a 
second stage juvenile (J2) which then hatches from the egg. The infective J2 migrates to a host root and feeds before molting into the third juvenile stage (J3) and then the fourth (J4). A final molt results in a reproductively mature adult. Under optimal conditions (suitable host plant, soil $\mathrm{pH}$ ranging from 5 to 8 , and soil temperatures between $28^{\circ} \mathrm{C}$ and $30^{\circ} \mathrm{C}$ ), the life cycle from egg to adult spans 25 days.

\subsubsection{Ecology}

Pratylenchus species are found in temperate, subtropical and tropical regions throughout the world. Population densities of lesion nematodes are affected by the biotic and abiotic factors of the soil ecosystem in which they are found. These soil parameters include microclimate (temperature and moisture), physical and chemical properties (soil type, percent organic matter, $\mathrm{pH}$, cation exchange capacity, salinity, nutrient availability), and species richness. The distribution and population densities of plant-parasitic nematode species vary based on soil type, texture, moisture, and temperature, as well as host crop (Norton, 1978).

Pratylenchus is found in coarse, sandy soils and sandy loam soils. Field populations of some species often are reported above the damage threshold in many coastal regions. Kotcon (1990) found differences in lesion nematode densities associated with soil type. Species of lesion nematodes have been observed in soils with temperatures ranging from $5^{\circ} \mathrm{C}$ to $38^{\circ} \mathrm{C}$ (Shurtleff and Averre, 2000; Bhan et al., 2010).

Shukla et al. (1997) compared effects of three soil pH levels on reproduction of Pratylenchus thornei on spearmint (Mentha spicata L.). They reported lowest and highest final populations at pH 3 and 9, respectively. In a greenhouse pot trial, Willis (1972) compared reproduction of $\mathrm{Pr}$. penetrans on alfalfa at four $\mathrm{pH}$ levels and observed greatest yield reduction and highest nematode reproduction at $\mathrm{pH}$ levels of 5.2 and 6.4 . 
Population densities and species richness of Pratylenchus varies with species and associated plant host. Based on observations of Pr. penetrans on 24 weed species, Bélair et al. (2007) reported highest lesion nematode reproduction on members of family Brassicaceae and lowest reproduction on members of family Cyperaceae. Kotcon (1990) reported seven species of Pratylenchus in soils sampled from peach orchards in the State of West Virginia.

Loof (1978) indicates several species of Pratylenchus often occur in mixed lesion nematode populations. Kotcon (1990) reported mixed populations of lesion nematodes and Xiphinema species in West Virginia peach orchard soils, and noted a positive correlation between population densities of Hoplolaimus and Pratylenchus species.

\subsubsection{Distribution}

At least 68 species of Pratylenchus parasitize more than 500 plant species and occur in and near tropical, subtropical, and temperate zones throughout the world. Mai et al. (1960) reported at least one species of Pratylenchus present in 12 states in the northeastern United States. Kotcon (1990) reported Pratylenchus species in 77\% of samples surveyed from West Virginia peach orchards. Loof (1978) noted that the most common lesion nematode species, $P r$. penetrans, Pr. crenatus, Pr. vulnus, Pr. thornei, Pr. neglectus, Pr. brachyurus, Pr. zeae, Pr. coffeae, and Pr. hexincisus are widely distributed across all continents.

Pratylenchus penetrans and Pr. crenatus often occur in mixed populations and are reported among the five most common lesion nematode species in northeastern North America (Townshend et al., 1978). Mai et al. (1977) stated that Pr. penetrans "is the most economically important plant-pathogenic nematode in the northeastern states" of the US. It is also a significant pest of potato in several states of the Pacific Northwest, as well as Canada and Europe (McKeen and Mountain, 1960; Bélair et al., 2007; Smiley et al., 2008). 


\subsubsection{Management practices}

Pratylenchus penetrans parasitizes more than 400 hosts, including conifer and fruit trees, strawberries, legumes, grasses, cereals, tomato, tobacco, potato, horticultural plants, and several weed species (Corbett, 1970; Corbett, 1973; Mai et al., 1977; Ferris and Ferris, 1998). These nematodes cause significant yield losses in many agricultural, horticultural, and forestry-related industries (Mai et al., 1977; Ferris and Ferris, 1998; Westerdahl et al., 2003; Bélair et al., 2007; Smiley et al., 2008). Some plant diseases caused by Verticillium, Rhizoctonia, and Fusarium show increased severity when Pr. penetrans is present, and this nematode is involved in other fungal, viral, and bacterial plant disease complexes (McKeen and Mountain, 1960; Loof, 1978; Dropkin, 1989; Jin et al., 1991; Barker et al., 1998; Saeed et al., 1998; Shurtleff and Averre, 2000; LaMondia, 2003).

In a survey of density and frequency of plant-parasitic nematodes recovered from crop production soils, Anwar et al. (2010) reported Pr. penetrans in 30\% of 325 soils sampled from 19 vegetable crops. They found that population densities of Pr. penetrans and M. incognita were at "potentially damaging levels in most of the vegetable crops surveyed." Hollaway et al. (2008) detected Pr.penetrans in Australian cereal crop soils and were concerned about the lack of current management options based on prior reports of damaging Pr. penetrans infestations in pea, wheat, and oat.

Pest management practices used to control most plant-parasitic nematodes are ineffective for controlling Pr. penetrans (Mai et al., 1977; Cook and Baker, 1983; Bélair et al., 2007). Lesion nematodes may survive more than a year in the absence of a host (Sher and Allen, 1953; Loof, 1961; Dropkin, 1989; Bélair et al., 2002). Cobb (1917) notes that their broad host range can compromise efficacy of crop rotation in infested field soils. Chemical nematode controls are 
available for some, but not all, conventional cropping systems, and demand for biological controls to manage these pests is increasing.

A few studies verify effective biological control of Pr. penetrans. Some success has been observed with cropping sequences that rotate specific varieties of plants which are either poor hosts or are known to be suppressive to lesion nematodes (Bélair et al., 2007; Bhan et al., 2010). Examples of plants that reduce populations of Pr. penetrans include species of marigold (Tagetes patula and T. erecta), hybrid cultivars of forage and grain pearl millet (Pennisetum glaucum L.), wheat (Triticum aestivum cv. Stacy), and oat (Avena strigosa cv. Saia) (Loof, 1978; Dropkin, 1989; Ball-Coelho et al., 2003; Bélair et al., 2005; LaMondia, 2006). In Canada, cropping systems utilize pearl millet as biocontrol of lesion nematodes on potato (Bélair et al., 2005).

Additional biological control agents and crop production practices are being investigated as alternatives to chemical treatments that reduce populations of Pr. penetrans (Westerdahl et al., 2003; Pal and McSpadden Gardener, 2006; Bélair et al., 2007). Hackenberg et al. (2000) reported suppression of Pr. penetrans on apple seedlings as well as in field and pot cultures of strawberry treated with Pseudomonas chlororaphis strain Sm3. Timper and Brodie (1994) indicated inconsistent suppression of Pr. penetrans by Hirsutella rhossiliensis. However, additional studies of interactions between this fungal species and lesion nematodes are warranted.

Endospores of Pasteuria have been reported on lesion nematodes for several decades. Infection of Pr. brachyurus by Pasteuria thornei is well documented. The current and potential threat that Pratylenchus penetrans poses to agricultural crop production warrants further investigations of the interactions between this highly virulent species and Pasteuria species. 


\subsection{Organic Agriculture}

United States Federal Code defines organic production as, "A production system that is managed in accordance with the Act and regulations in this part to respond to site-specific conditions by integrating cultural, biological, and mechanical practices that foster cycling of resources, promote ecological balance, and conserve biodiversity" (USDA, 2010). The term "organic farming" was first used in 1941, when Northbourne described it as the management of all aspects of a farming system incorporating animals, plants, civilization, and the soil (Lotter, 2003). Conventional agriculture systems rely heavily on synthetic fertilizers and pesticides, such as nematicides, to maintain and increase crop production, whereas organic systems do not (Lotter, 2003; Pimentel et al., 2005).

Research comparing organic and conventional farming systems indicates reduced environmental and human health risks associated with organic practices compared with conventional methods (Reganold et al., 2001; Lotter, 2003; Pimentel, 2005; Pimentel et al., 2005). Based on a 22-year study of organic and conventional cropping systems, Pimentel et al. (2005) reported that organic cropping systems reduce chemical pollutants, fossil energy inputs, soil erosion, and surface runoff and increase soil organic matter, soil biodiversity, water conservation, and drought tolerance.

Consumers are increasingly aware of the ecological and nutritional benefits of sustainably manufactured products, and the demand for organic goods continues to rise (Lotter, 2003; Sooby et al., 2007; International Federation of Organic Agriculture Movements (IFOAM), 2012). In 2011, worldwide sales of organic goods exceeded $\$ 62$ billion, a four-fold increase since 1999 (IFOAM, 2012). Nearly half of these sales were in the United States, which is the leading consumer of organically manufactured products (IFOAM, 2012). The fruit and vegetable 
market is the highest area of consumer demand for organic products, accounting for $43 \%$ of demand in 2012 (USDA/ERS, 2015). To meet growing consumer demand, organic growers must increase yields while using natural, non-chemical methods mandated by government guidelines for certified organic crop production (Lotter, 2003; Sooby et al., 2007; USDA, 2010).

Annual global economic losses associated with damage and diseases caused by plantparasitic nematodes have been estimated at 12 billion - 100 billion dollars (Sasser and Freckman, 1987; Bird and Koltai, 2000). Damage caused by plant disease depends on the damage threshold, which is the pest population level that the crop can withstand before yield losses occur. Some chemical pesticides used to control plant-parasitic nematodes require higher application dosages than the amount needed to manage other agricultural pests (Johnson and Feldmesser, 1987; Thomason, 1987). Evidence of environmental and human health risks associated with these treatments has resulted in restricted or revoked use of most commercial nematicides (Johnson and Feldmesser, 1987; Thomason, 1987; Nordmeyer, 1992; Pimentel, 2005).

The United States Environmental Protection Agency (EPA) banned use of nematicidal soil fumigants containing 1,2-dichloropropane (1,2-D), ethylene dibromide (EDB), and 1,2dibromo-3-chloropropane (DBCP) in the 1980s. Since then, the majority of pesticides used for nematode control have been discontinued by the manufacturer or restricted to non-nematicidal use (Johnson and Feldmesser, 1987; Nordmeyer, 1992). Aldoxycarb, fenamiphos, and carbofuran were cancelled or discontinued in 2005,2007 , and 2009, respectively. The remaining nematicides, such as methyl bromide, metam-sodium, and 1,3-dichloropropene (1,3-D), also are at risk for cancellation or restricted use in the future (Thomason, 1987; Nordmeyer, 1992).

Organic agriculture replaces use of conventional chemical pesticides with use of biological control practices that promote plant vigor and reduce populations of plant pests and 
pathogens. Innovative pest management methods and biological alternatives to chemical nematicides are needed to control plant-parasitic nematodes in both organic and conventional farming systems (Pimentel, 2005). Investigations of the biological control potential of naturally occurring antagonists of plant pathogens, which have been identified from field soils, are underway throughout the world. Continued studies of natural plant-disease suppression, especially in organic crop production soils, may lead to discoveries of additional biological controls for plant-parasitic nematodes (Kerr, 1982; Cook and Baker, 1983; Jatala, 1986; Sikora, 1992; Stirling, 1992; Hallman et al., 2007).

The West Virginia University Horticulture Research Farm was established in 1916 for conventional crop production research. The farm was designated for organic agriculture research in 1999, after which a transition from conventional to organic production began. The WVU Organic Research Farm has been certified organic by the Ohio Ecological Food and Farm Association since 2003. Although specific nematode management has not been implemented, populations of plant-parasitic nematodes in these soils have not increased in the presence of suitable host crops (Kotcon, 2006; Kotcon, 2010). This suggests these soils are suppressive to plant-parasitic nematodes, including Pratylenchus. Although endospores of Pasteuria were observed previously on root-lesion nematodes from these soils, the nature of suppression was not determined.

\subsection{Biological Control and Disease Suppressive Soils}

The objective of biological control is to utilize a natural, non-chemical approach to reduce severity of plant diseases and increase crop yield (Kerr, 1982; Jatala, 1986; Kerry, 1990; Sikora, 1992; Stirling, 1992; Pal and McSpadden Gardener, 2006; Stevens and Stuart, 2008). Biological control in agricultural crop production has been loosely defined as any practice that 
preserves, increases, or introduces naturally occurring antagonists of plant pathogens. A biological control agent is a living organism that disrupts infection or infestation of a plant host by one or more pathogens (Norton, 1978; Kerr, 1982; Cook and Baker, 1983; Pal and McSpadden Gardener, 2006).

Sikora (1992) described two types of biological control practices. Augmentative biocontrol practices are "the 'classical' approach of managing the antagonistic potential ... of a soil" and inundative biocontrol systems are "based on repeated application of biological agents" (Sikora, 1992). Therefore, augmentative practices may increase existing populations of Pasteuria present in soils; whereas, inundative methods involve direct application of Pasteuria endospores into soils. Augmentative biocontrol methods involve the use of soil amendments to suppress pathogens and enhance plant growth. These practices increase soil quality, organic matter, and populations of native organisms to maintain or promote natural disease suppression in cultivated soil systems (Sikora, 1992; Lotter, 2003; Janvier et al., 2007). Crops cultivated in soils amended with organic matter grow vigorously and maintain natural host defenses against plant pathogens (Coyne and Thompson, 2006 Pimentel et al., 2005; Janvier et al., 2007). Amended soils have higher populations of indigenous soil organisms, such as beneficial microorganisms and antagonists of plant pathogens, compared to non-amended soils (Sikora, 1992; Pimentel et al., 2005; Coyne and Thompson, 2006; Janvier et al., 2007).

Based on greenhouse and field studies of four types of organic amendments tested in cocoa production soils, Fademi et al. (2010) reported induced suppression of root-knot nematodes in all amended soils, but no suppression in non-amended control treatments. In addition to organic soil amendments, examples of augmentative biocontrols include mechanical weed control, monitoring pest populations, choosing disease-free seed and rootstock, 
intercropping and rotating crops, and planting disease resistant cultivars (Mankau, 1968; Sikora, 1992; Coyne and Thompson, 2006; Janvier et al., 2007).

Inundative methods involve direct application of beneficial organisms and/or biological control agents to reduce pathogen populations. Biocontrol agents are a specific class of beneficial organisms that reduce plant disease by direct antagonism of pests. Other types of beneficial organisms, such as some rhizobacteria species, promote plant vigor and support natural plant host defense mechanisms.

Biocontrol agents include select viruses and species of bacteria, fungi, and invertebrates that are naturally antagonistic to plant pathogens (Norton, 1978; Kerr, 1982; Cook and Baker, 1983; Stirling, 1992; Pal and McSpadden Gardener, 2006). Pioneer uses of commercial biocontrol agents occurred in 1962, with the use of Peniophora gigantea to control Heterobasidium annosum, and in 1973, with the use of Agrobacterium radiobacter strain 84 to control Agrobacterium tumefaciens (Kerr, 1982). Some known biocontrol agents include Bacillus, Pasteuria, Pseudomonas, and Streptomyces species, as well as fungi such as Aspergillus flavus, Coniothyrium minitans, Venturia inequalis, Trichoderma, and Gliocladium species (Kerr, 1982; Cook and Baker, 1983; Dong and Zhang, 2006; Pal and McSpadden Gardener, 2006; Tian et al., 2007).

While many of these microbes have been formulated into biological pesticides that target bacterial and fungal plant pathogens, only a few target plant-parasitic nematodes. Biological nematicides have been formulated and are registered with the US EPA and approved by the Organic Materials Review Institute for use in organic agriculture. Examples include DiTera, a product of fermented Myrothecium verrucaria, MeloCon WG, a formulation of Paecilomyces lilacinus strain 251, and Nema-Q, an extract of Quillaja saponaria. 
Few studies have investigated biological control of plant-parasitic nematodes in organic crop production soils. Pokharel and Zimmerman (2010) compared nematode populations recovered from two peach cultivars planted in organic and conventional peach orchards. Average population densities of plant-parasitic nematodes in soils from both peach varieties were lower in the conventional orchard than in the organic orchard. Authors noted the highest densities of plant-parasitic nematodes occurred in soils from one of the conventionally grown varieties. Diversity of bacterial and fungal feeders, as well as plant-parasitic nematodes, was greater in soils from both cultivars in the organic orchard than in the conventional orchard. These authors detected species in five genera of plant-parasitic nematodes including Pratylenchus and Meloidogyne.

Atkins et al. (2003) demonstrated that the nematophagous fungus, Pochonia chlamydosporia var catenulate, reduced populations of root-knot nematodes in organically managed soils when combined with crop rotation. Combinations of Neem oil and organic amendments, as well as treatments using Paecilomyces lilacinus, show promise for use in biological control of Meloidogyne species (Rao et al., 1997; Oka et al., 2007). Neem oil is extracted from the leaves of the Neem tree, Azadirachta indica, and may have potential for biocontrol of plant-parasitic nematodes.

\subsubsection{Suppressive soils}

Discovery of new biological control agents often begins with observation of prolonged periods of low disease incidence in the presence of suitable host crops, especially in untreated soils such as those found in organic cropping systems (Cook and Baker, 1983; Sikora, 1992; Lotter, 2003). Disease suppressive soils maintain plant pathogen populations below the damage threshold in the presence of susceptible hosts, and these soils have been identified in organic, 
conventional, and non-cultivated systems (Shipton et al., 1973; Cook and Baker, 1983; Barker et al., 1998; Westphal and Becker, 2000; Pyrowolakis et al., 2002; Rimé et al., 2003; Bao et al., 2010; Kotcon unpub.). Conducive soils, in contrast, allow plant pathogen populations to increase above the damage threshold and cause significant yield losses.

Sikora (1992) stated that "the level of antagonism in soil may vary from total suppression to stimulation of a specific nematode pest or disease." In some cases, controlled experiments reveal biotic causes of suppression and lead to isolation of one or more potential biocontrol agents, which may then be evaluated for suppressive or antagonistic effects upon targeted plant pathogens (Cook and Baker, 1983; Sayre, 1986; Stirling, 1992; Barker et al., 1998; Pal and McSpadden Gardener, 2006). General suppression is attributed to a range of living and nonliving soil factors; whereas, specific soil suppressiveness is caused by one living organism (Cook and Baker, 1983; Pal and McSpadden Gardener, 2006). Soils with specific nematode suppressiveness have been identified at several field sites (Dickson et al., 1992; Kluepfel et al., 1993; Westphal and Becker, 2000; Pyrowolakis et al., 2002; Westphal, 2005).

A determining factor for specific suppression is transferability of disease suppressiveness to non-suppressive or disease conducive soils (Cook and Baker, 1983). Shipton et al. (1973) reported transfer of microbial antagonism of take-all decline in wheat by adding $1 \%$ antagonistic soil to fumigated field and steamed greenhouse soils. Sterilized soils inoculated with Pasteuria penetrans-infested soil can develop suppressiveness to Meloidogyne incognita in greenhouse pot culture (Mankau, 1975). A number of subsequent reports indicated that specific soil suppression of root-knot nematodes by Pasteuria species was likely based on transferability of suppression (Oostendorp et al., 1991a; Chen et al., 1996b; Weibelzahl-Fulton et al., 1996; Freitas et al., 2000; Kariuki and Dickson, 2007). 


\subsection{Conclusion}

A variety of biological control products are available to reduce bacterial and fungal plant pathogens; however, development of biological nematicides and alternative methods for suppression of plant-parasitic nematodes is needed. Recent research indicates that species of Pasteuria have the potential to meet this need for nematode biocontrol. Interactions between Pasteuria and select species of economically important plant-parasitic nematodes have been studied, yet only a minor fraction of this research has been conducted on Pratylenchus species. 


\subsection{RESEARCH OBJECTIVES}

Objective 1. Assess the geographic distribution and frequency of Pasteuria and Pratylenchus species in certified organic crop production soils collected from the Mid-Atlantic region of the United States. Population density of Pratylenchus will be correlated with the following soil variables: presence of Pasteuria, soil type, soil pH, cation exchange capacity, and mineral availability of potassium, phosphorus pentoxide, calcium, and magnesium.

Objective 2. Determine if nematode suppressiveness of West Virginia University Organic Research Farm soils is caused by biotic or abiotic factors and determine effects of soil volume on density of Pratylenchus penetrans in pot culture. Mean density of Pratylenchus penetrans infecting Phaseolus vulgaris cv. Jade is expected to be lower in non-sterile than in sterile soil treatments, but not statistically different among soil volume treatments.

Objective 3. Test the hypothesis that the mean rate of increase of Pratylenchus penetrans populations infecting Phaseolus vulgaris cv. Jade will be lower in soils containing Pasteuriaattached Pratylenchus nematodes than in soils where Pasteuria was not detected $(\mathrm{P}=0.10)$. 


\subsection{MATERIALS AND METHODS}

To test Objective 1, soils from organic farms in the Mid-Atlantic region were collected to determine presence of $P$ a. penetrans. A greenhouse baiting procedure was conducted on a subset of these samples. Lab bench trials were conducted to assess Objectives 2 and 3. Survey procedures are described in section 4.1, below. Nematode culture procedures are described in section 4.2. Experimental design, plant growth conditions, harvest methods, and data analysis procedures are described in sections $4.3,4.4,4.5$, and 4.6 , respectively.

Note: Nematode specimens of interest in these studies were photographed on 35-mm film using a Nikon OPTIPHOT differential interference contrast microscope fitted with a Nikon AFX-II camera. However, these images are not included because the 35-mm film was doubleexposed and all photographs were discarded.

\subsection{Collection of soils}

The survey of Pasteuria and Pratylenchus in organic cropping soils was conducted based on methods modified from Kotcon (1990). Soils were collected from crop-growing areas at certified organic farms in Maryland, Ohio, Pennsylvania, Virginia, and West Virginia (Table 4.1).

Between March and June 2008, certified organic growers were visited and interviewed to collect information regarding crop history and pest management practices. One to three 19-liter soil samples were collected from each farm. Each 19-liter sample was a composite of multiple samples taken from varying locations in the same crop growing area. A spade-tipped shovel was used to collect a 3- to 4-liter soil sample to a depth of 15 to $20 \mathrm{~cm}$ below the soil surface. Each sample was assigned an identification code indicating the farm where the sample was collected 
and the number of samples collected at that farm. Soils were transported to the WVU

Nematology laboratory and stored at $11 \pm 3^{\circ} \mathrm{C}$ for 2 to 4 weeks.

In November 2008, a 19-liter soil sample was collected from WVU Organic Research Farm vegetable plots using the same method described herein. The soil sample was stored in the WVU Nematology laboratory at $20 \pm 3^{\circ} \mathrm{C}$ for 6 days.

Visible debris and macro organisms were removed and each soil sample was hand mixed for 5 to 6 minutes. A $500-\mathrm{cm}^{3}$ subsample was stored at $11 \pm 3^{\circ} \mathrm{C}$ for nematode extraction and a 20- $\mathrm{cm}^{3}$ subsample was analyzed by the WVU Soil Testing Laboratory to determine soil $\mathrm{pH}$, cation exchange capacity, and cation concentrations. Remaining soil was stored at $11 \pm 3^{\circ} \mathrm{C}$ for use in future studies. Soil types and textures were determined based on the geographic location of each farm using the USDA Natural Resources Conservation Service Web Soil Survey (2009).

Table 4.1. Fifteen counties from five Mid-Atlantic states represented in the survey of Pasteuria on Pratylenchus from certified organic cropping soils.

\begin{tabular}{ll}
\hline State & County or Counties \\
\hline Maryland & Baltimore, Frederick, Washington \\
Ohio & Athens, Noble, Wayne \\
Pennsylvania & Allegheny, Beaver, Butler, Huntingdon, Indiana, Somerset, Westmoreland \\
Virginia & Madison \\
West Virginia & Preston \\
\hline
\end{tabular}

\subsection{Host nematode cultures}

Inocula consisting of mixed life stages of Pratylenchus penetrans were obtained from two sources. A population of Pr. penetrans established from a single female isolated from Prunus sp. was maintained on Zea mays cv. Doebblers N659 in WVU greenhouse pot cultures. This population was maintained by harvesting corn plants at 8-week intervals and direct-seeding corn into nematode infested soil. Nematodes extracted from this culture were used for the preliminary experiment on WVU Organic Research Farm soils. Nematodes were extracted from 
corn roots using the shaker extraction method for 9 days followed by incubation of roots on Baermann funnels for an additional 10 days (Niblack and Hussey, 1985; Barker et al., 1986). Axenic root explant cultures of Pr. penetrans on Zea mays (IO Chief) were provided by the USDA Agricultural Research Service Nematology laboratory in Beltsville, MD. This population was established from a single Pr. penetrans female isolated from lawn soils at USDA-ARS, Beltsville, MD (L. Carta, pers. commun.). This population of Pr. penetrans (ARSMD isolate) was increased by aseptically transferring subsections of nematode-infested root explants from established plates to fresh corn root explants on potato dextrose agar. Culture plates were stored in the WVU Nematology laboratory at $20 \pm 3^{\circ} \mathrm{C}$. This population was used for the experiment that compared reproduction of Pr. penetrans in soils with and without Pasteuria. Nematodes were extracted from corn root explants in agar using the Baermann funnel method (Niblack and Hussey, 1985; Barker et al., 1986).

\subsection{Experimental design and preparation of treatments}

\subsubsection{Increasing detection of Pasteuria}

Some of the soils collected for the survey of lesion nematodes and Pasteuria were suspected to have Pasteuria at levels below detection because endospores were observed on Pratylenchus in samples taken from other cropping areas at the same farm. A greenhouse baiting trial was conducted to increase detection of Pasteuria on Pratylenchus in six soil samples. For

each soil sample, $600 \mathrm{~cm}^{3}$ of untreated soil was hand mixed and then divided to fill two $400-\mathrm{cm}^{3}$ plastic pots with $300 \mathrm{~cm}^{3}$ soil in each. Corn (Zea mays) cv. Doebblers N659 and green bean (Phaseolus vulgaris) cv. Jade were each direct-seeded into separate pots of the same soil.

\subsubsection{Reproduction of Pr. penetrans in four soil treatments}


To assess differences in reproduction of Pratylenchus penetrans in sterilized versus nonsterilized WVU Organic Research Farm soil, methods described by Timper and Brodie (1994), Weibelzahl-Fulton et al. (1996), Hackenberg et al. (2000), Bélair et al. (2007), and Jaffee et al. (2007) were modified. Four soil treatments were prepared with soil collected from the WVU Organic Research Farm: (i) sterilized soil, (ii) non-sterile soil, (iii) 90:10 soil (90\% sterile and $10 \%$ non-sterile soil), and (iv) a non-sterile, uninoculated soil.

Two types of planting containers were used: (i) $400 \mathrm{~cm}^{3}$ of soil treatments in $500-\mathrm{cm}^{3}$ plastic pots, or (ii) $150 \mathrm{~cm}^{3}$ of soil treatments in $250-\mathrm{cm}^{3}$ glass beakers.

Sterile sand was mixed 1:1 (v/v) with the soil sample and moistened. The sterile soil treatment was prepared by steaming a $4,000-\mathrm{cm}^{3}$ subsample in an autoclave at $80^{\circ} \mathrm{C}$ for 70 minutes (Chen et al., 1996b). The remaining untreated soil was stored in the laboratory at 20 $\pm 3^{\circ} \mathrm{C}$. After autoclaving, the sterilized soil cooled on the laboratory bench for $24 \pm 3$ hours. Soil treatments were then added to the planting containers. Three replicates each of the four soil treatments in the two types of planting containers were arranged in a randomized factorial experiment conducted on a bench top in the WVU Nematology laboratory. Green beans were germinated in sterile soil at $20 \pm 3^{\circ} \mathrm{C}$ for 11 days, with one seedling planted per container.

The first three treatments were inoculated with a suspension of $58 \pm 6$ Pr. penetrans inoculum prepared as described in section 4.2, and the fourth treatment served as an uninoculated control. The uninoculated control treatments were added to the bench 4 weeks after the three inoculated treatments were planted.

\subsubsection{Reproduction of Pr. penetrans in soils with and without Pasteuria}

Six soils containing Pasteuria endospores were matched with soils of similar soil $\mathrm{pH}$, soil type and soil texture in which Pasteuria endospores were not detected (Table 4.2). A total of 144 
pots were arranged in three blocks of eight soil treatments in a randomized complete block, fourway factorial design. The blocking variable was time between planting, and treatment variables were 1) presence or absence of Pasteuria, 2) soil with or without inoculum consisting of $277 \pm$ 11 mixed life stage nematodes of Pr. penetrans, 3) harvest time of 2 or 8 weeks, and 4) soil type.

Sterile sand was mixed 1:1 (v/v) with each soil sample. A 9- $\mathrm{cm}^{3}$ subsample was analyzed to determine percent organic matter content (carbon and nitrogen) in the WVU Soil Chemistry Laboratory under the direction of Dr. Louis M. McDonald (Table 4.2). Green beans cv. Jade were germinated in sterile sand for 5 days at $20 \pm 3^{\circ} \mathrm{C}$. Sterilized plastic pots were filled with $1,000-\mathrm{cm}^{3}$ of the sand/soil mixture. Soils were dried in pots for $19 \pm 3$ hours at $66 \pm 16^{\circ} \mathrm{C}$ in drying ovens to reduce background populations of lesion nematodes without affecting viability of Pasteuria endospores (Timper and Brodie, 1994; Jaffee et al., 2007). Each pot contained one green bean seedling.

Table 4.2. Soil pH, soil type, soil texture and organic matter content (percent carbon and nitrogen) of six soil pairs used in an experiment to compare reproduction of Pratylenchus penetrans on Phaseolus vulgaris in soils with and without Pasteuria.

\begin{tabular}{lcccllcc}
$\begin{array}{l}\text { Sample } \\
\text { Code }\end{array}$ & $\begin{array}{c}\text { Soil } \\
\text { Pair }\end{array}$ & $\begin{array}{c}\text { Pasteuria } \\
\text { detected }(+/-)\end{array}$ & $\begin{array}{c}\text { Soil } \\
\mathrm{pH}\end{array}$ & $\begin{array}{l}\text { Soil } \\
\text { Type }\end{array}$ & $\begin{array}{l}\text { Soil } \\
\text { Texture }\end{array}$ & $\begin{array}{c}\text { \% Carbon } \\
(\mathrm{OM})\end{array}$ & $\begin{array}{c}\text { \% Nitrogen } \\
(\mathrm{OM})\end{array}$ \\
\hline MD2A & 1 & + & 6.4 & Hapludalf & Fine & 2.29 & 0.18 \\
MD24 & 1 & - & 6.3 & Hapludalf & Fine-loamy & 1.30 & 0.06 \\
\hline MD2B & 2 & + & 7.2 & Hapludalf & Fine & 2.11 & 0.13 \\
MD4 & 2 & - & 7.2 & Hapludalf & Fine & 3.57 & 0.33 \\
\hline PA17A & 3 & + & 6.4 & Hapludult & Fine-loamy & 2.11 & 0.12 \\
PA18 & 3 & - & 6.7 & Hapludult & Fine-loamy & 3.09 & 0.21 \\
\hline PA15C & 4 & + & 6.9 & Fragiudalf & Fine-loamy & 2.66 & 0.20 \\
MD22 & 4 & - & 6.4 & Fragiaqualf & Fine-silty & 1.26 & 0.06 \\
\hline PA11B & 5 & + & 6.5 & Dystrochrept & Loamy-skeletal & 1.64 & 0.10 \\
PA12 & 5 & - & 6.9 & Endoaquult & Fine & 2.22 & 0.23 \\
\hline PA16 & 6 & + & 5.5 & Dystrochrept & Loamy-skeletal & 1.58 & 0.11 \\
PA17C & 6 & - & 6.0 & Fragiudult & Fine-loamy & 1.61 & 0.15 \\
\hline SOil
\end{tabular}

Soil types and textures were determined using the USDA NRCS Web Soil Survey (http://websoilsurvey.nrcs.usda.gov). Organic matter analyses were performed by the WVU Soil Chemistry Research Laboratory under the direction of Dr. Louis M. McDonald. 


\subsection{Plant growth conditions}

\subsubsection{Increasing detection of Pasteuria}

Green bean and corn plants were thinned to one plant per pot after 7 days and were grown in the greenhouse at $23 \pm 2^{\circ} \mathrm{C}$. Green bean and corn were harvested after 9 and 12 weeks, respectively.

\subsubsection{Reproduction of Pr. penetrans in four soil treatments}

One 400-watt metal halide lamp (Sunlight Supply, Inc. Vancouver, WA, USA) placed $112 \mathrm{~cm}$ above soil surfaces provided supplemental light with an 8-hour photoperiod. Light intensity was not measured. Soil moisture content was determined by comparing the weight of a $10-\mathrm{cm}^{3}$ subsample before and after drying in an oven at $45^{\circ} \mathrm{C}$ for 24 hours, and plants were watered daily to maintain soil moisture at approximate field capacity.

\subsubsection{Reproduction of Pr. penetrans in soils with and without Pasteuria}

Four metal halide lamps (P.L. Light Systems, Beamsville, ON, Canada LOR 1B1) placed $112 \mathrm{~cm}$ above soil surfaces provided supplemental light with a 10-hour photoperiod (Kotcon et al., 1987). Light intensity was not measured. The average amount of water lost from all plants in a 24-hour period was calculated every 3 weeks and used to determine the volume of sterile distilled water to add to each plant per day.

\subsection{Harvest methods and nematode assays}

\subsubsection{Survey of Pasteuria on Pratylenchus in certified organic cropping soils}

Nematodes were extracted from soil using the modified sucrose-centrifugation method, and extraction solutions were stored at $11^{\circ} \mathrm{C}$ for observation (Jenkins, 1964; Panaccione et al., 2006). Nematodes were examined at 60 to 120 X magnification with a Nikon SMZ660 stereo light microscope. Nematodes of interest were hand-picked and prepared for oil immersion 
microscopy, which was performed with a Nikon OPTIPHOT differential interference contrast light microscope at 125 to $600 \mathrm{X}$ magnification. Nematodes examined under oil immersion were observed for attachment of Pasteuria endospores and identified to genus and species. Population density and frequency of Pratylenchus and Pasteuria were recorded. The number of lesion nematodes was extrapolated from partial counts for two samples (PA14 and PA16).

\subsubsection{Increasing detection of Pasteuria}

To extract nematodes from roots, plants were destructively harvested and roots were rinsed with tap water and blotted dry. Fresh root weight was recorded. Up to 1 gram of root was placed in a $125-\mathrm{ml}$ flask with $50 \mathrm{ml}$ of tap water, and flasks were incubated on a rotary shaker at $150 \mathrm{rpm}$ at $20 \pm 3^{\circ} \mathrm{C}$ for 4 days (Barker et al., 1986). Each shaker solution was poured through a $710-\mu \mathrm{m}$-pore sieve to remove root debris. Nematodes were collected on a $15-\mu \mathrm{m}$-pore sieve, transferred to a test tube, and stored at $11 \pm 3^{\circ} \mathrm{C}$ for 1 to 6 days (Barker et al., 1986).

Lesion nematodes extracted from roots were counted, microscopically examined for attachment of Pasteuria endospores, and identified to species, when possible, using the same methods previously described. Nematodes were not recovered from soils.

\subsubsection{Reproduction of Pr. penetrans in four soil treatments}

Plants were harvested 8 weeks after transplanting. Up to 1 gram of root was incubated on a shaker, and nematodes were extracted at 3-day intervals for 9 days. Nematodes were examined at 60 to $120 \mathrm{X}$ magnification with a Nikon SMZ660 stereo light microscope. One to 14 lesion nematodes per sample were examined for Pasteuria endospores. Population density and frequency of Pratylenchus and Pasteuria were recorded. When less than 1 gram root weight was recovered from a harvested plant, densities of Pratylenchus species, Pr. penetrans, and Pr. crenatus per gram root were extrapolated from actual counts. 


\subsubsection{Reproduction of Pr. penetrans in soils with and without Pasteuria}

Half of the 48 plants in each block were harvested at 2 weeks after planting, with the remaining plants harvested at 8 weeks after planting. Fresh weight of the roots of each plant was measured. The shaker method (Kotcon et al., 1987) was used to extract nematodes from up to 1 gram root. Nematodes were recovered from shaker solutions at 2-day intervals for 4 days. For the 8-week harvest, fresh shoot weights were recorded, then oven-dried at $40^{\circ} \mathrm{C}$ for 5 days to determine shoot dry weight.

Soils were stored in zip closure bags at $11 \pm 3^{\circ} \mathrm{C}$ for 7 to 10 days, and nematodes in soil were extracted using the modified sucrose-centrifugation method (Jenkins, 1964; Panaccione et al., 2006). Nematodes from root and soil samples were examined with a Nikon SMZ660 stereo light microscope at 60 to $120 \mathrm{X}$ magnification, and all lesion nematodes were prepared for oil immersion microscopy with a Nikon OPTIPHOT differential interference contrast light microscope at $600 \mathrm{X}$ magnification. Nematodes were identified to species and scanned for presence of Pasteuria endospores.

\subsection{Data analyses}

For the survey of Pasteuria on lesion nematodes in certified organic cropping soils, data were divided into three subsets based on presence of Pratylenchus and presence or absence of Pasteuria on lesion nematodes. Means, standard error, and correlation coefficients for soil parameters were calculated. R-values were significant at or above $|0.33|$. The assay conducted to increase detection of Pasteuria on lesion nematodes was not replicated and data analyses were not performed. Results are based on observations of nematodes found in roots from one plant grown in a single pot per each subsample of soil. The number of lesion nematodes recovered for samples MD2A and PA17A were not included for analyses of Pratylenchus densities in the 
survey data. Detection of Pasteuria on Pratylenchus in sample MD2A was included in the survey data.

For the experiment that compared reproduction of Pr. penetrans in four soil treatments, one-way and two-way interactions were analyzed using the Least Squares Model with statistical significance at $\mathrm{P} \leq 0.05$.

For the experiment that compared reproduction of Pr. penetrans in soils with and without Pasteuria, densities of Pr. penetrans in the 2- and 8-week harvests were compared to determine treatment effects on lesion nematode populations. Total nematode density per plant was calculated as a sum of the products of the number of nematodes extracted per unit of extraction

( $\leq 1$ gram root or $100-\mathrm{cm}^{3}$ soil), total fresh root weight, and total soil volume (Kotcon et al., 1987). Data were $\log$ transformed $\left(\log _{10}[\mathrm{x}+1]\right)$ to normalize zero counts, and treatment effects and interactions were analyzed using four-way analysis of variance. One-way, two-way, threeway and four-way interactions were analyzed using the Least Squares Model and were considered statistically significant at $\mathrm{P} \leq 0.10$. Unless otherwise noted, data were reported as untransformed means.

All data analyses were performed using JMP statistical software (SAS Institute Inc., Cary, North Carolina, USA).

\subsection{RESULTS}

\subsection{Survey of Pasteuria on Pratylenchus in certified organic cropping soils}

Pratylenchus were present in 22 of 34 samples from 25 farms in Maryland, Ohio, Pennsylvania, Virginia, and West Virginia (Figure 5.1). The geographic locations of the farms included in the survey was dependent upon grower response to solicitation. 
Species were not determined for two samples due to absence of adult nematode stages. The number of lesion nematodes recovered ranged from one to 80 in the 22 samples in which they were present (Figure 5.2). For all but two samples, all lesion nematodes recovered were observed for endospores of Pasteuria. For sample PA14, 20 Pratylenchus were observed out of an estimated 80 total lesion nematodes recovered. For sample PA16, 10 of an estimated 20 lesion nematodes were observed. Nematode specimens lost or damaged during processing were reported as "Pratylenchus species unknown."

Endospores of Pasteuria were observed on lesion nematodes recovered from field populations in five soil assays and from roots in two samples, one of which was identified in the baiting trial to increase detection of Pasteuria (Table 5.1). The proportion of Pratylenchus with Pasteuria endospores ranged from $20 \%$ to $75 \%$ for soil extractions and $10 \%$ to $50 \%$ for root extractions (Table 5.2).

Mean population density of Pratylenchus nematodes among all 22 samples was $9.2 \pm 3.6$ per $100 \mathrm{~cm}^{3}$ soil. Densities were higher in the 16 soils without Pasteuria than in soils where Pasteuria was detected on lesion nematodes (Table 5.3); however, differences between means were not significant (Student's t-test, $\mathrm{P}=0.68$ ).

Correlations between lesion nematode density and tested soil parameters were not significant when all 34 samples were included in the analysis. Population density of Pratylenchus was positively correlated with soil $\mathrm{pH}$, cation exchange capacity and calcium when only the 22 samples with lesion nematodes were analyzed (data not shown). In the 16 soils in which Pasteuria were not detected on Pratylenchus, density of lesion nematodes was positively correlated with soil $\mathrm{pH}$, cation exchange capacity, calcium, and phosphorus content (Table 5.4). Lesion nematode population density in six soils with Pasteuria was negatively correlated with 
soil $\mathrm{pH}$, calcium, and phosphorus content, and positively correlated with magnesium content (Table 5.5). The range of soil $\mathrm{pH}$ levels for all samples was 4.9 to 7.3 and the mean was 6.5 (data not shown).

Organic growers emphasize high diversity of rotation and cover crops, so no statistical analysis of host crop history was possible. Host crop history is listed in Appendix A.

One lesion nematode from sample MD2B was suspected to be Pr. neglectus, but key morphological characteristics were not confirmed due to poor specimen quality. Additional nematode genera observed from these soils included Criconemoides, Helicotylenchus, Hoplolaimus, Meloidogyne, Mononchus, Paratylenchus and Tylenchus. In sample PA15C, endospores of Pasteuria were detected on both Pratylenchus and Hoplolaimus. Endospores of Pasteuria were not observed on lesion nematodes but were observed on Helicotylenchus in sample OH8 and on Hoplolaimus in sample PA19. 
Figure 5.1. Distribution of Pratylenchus and Pasteuria on Pratylenchus in soils collected from certified organic farms in Maryland, Ohio, Pennsylvania, Virginia, and West Virginia.

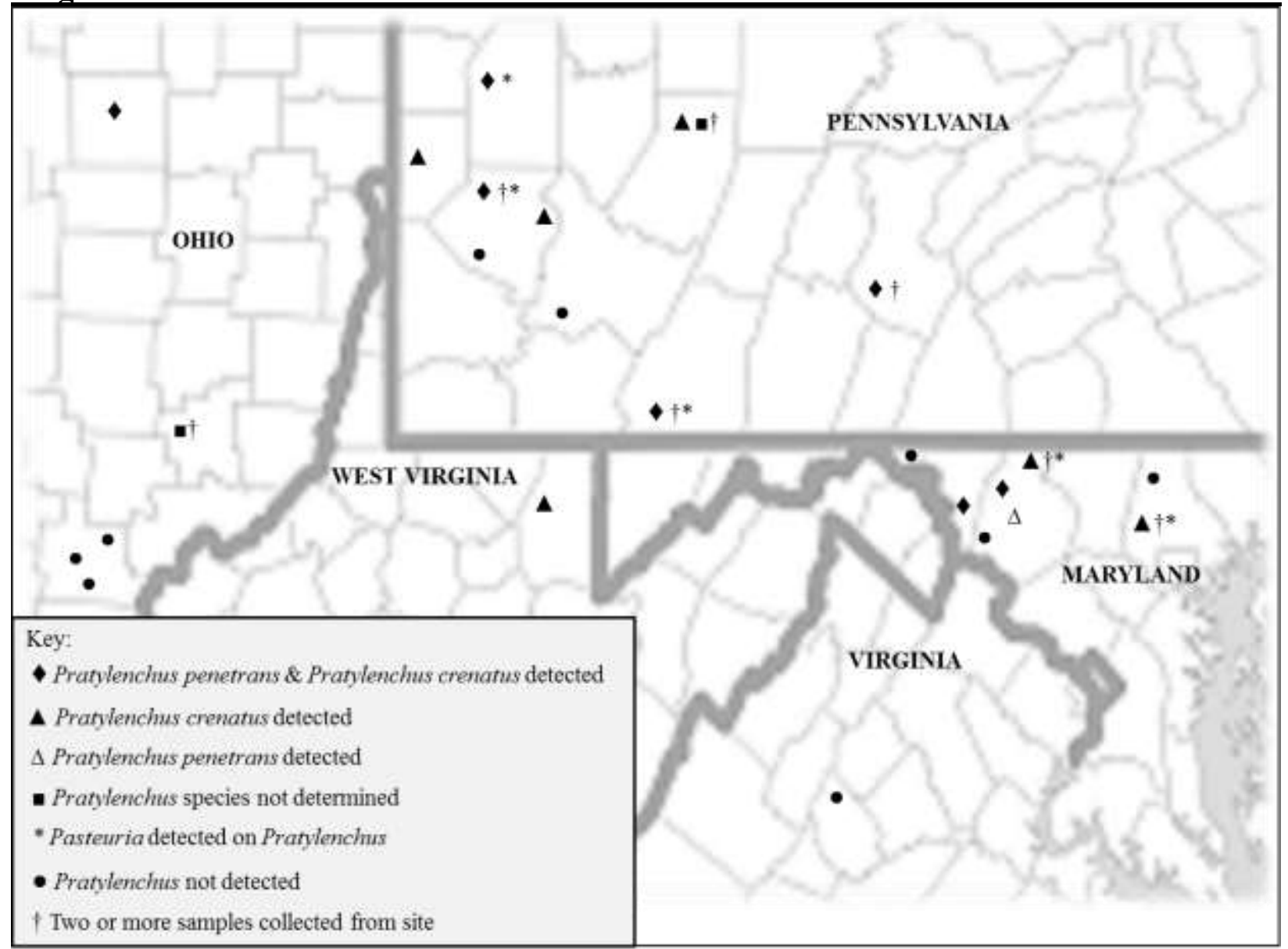


Figure 5.2. Frequency of Pratylenchus nematodes recovered from $100-\mathrm{cm}^{3}$ soil for 34 samples collected from certified organic farms in the Mid-Atlantic states.

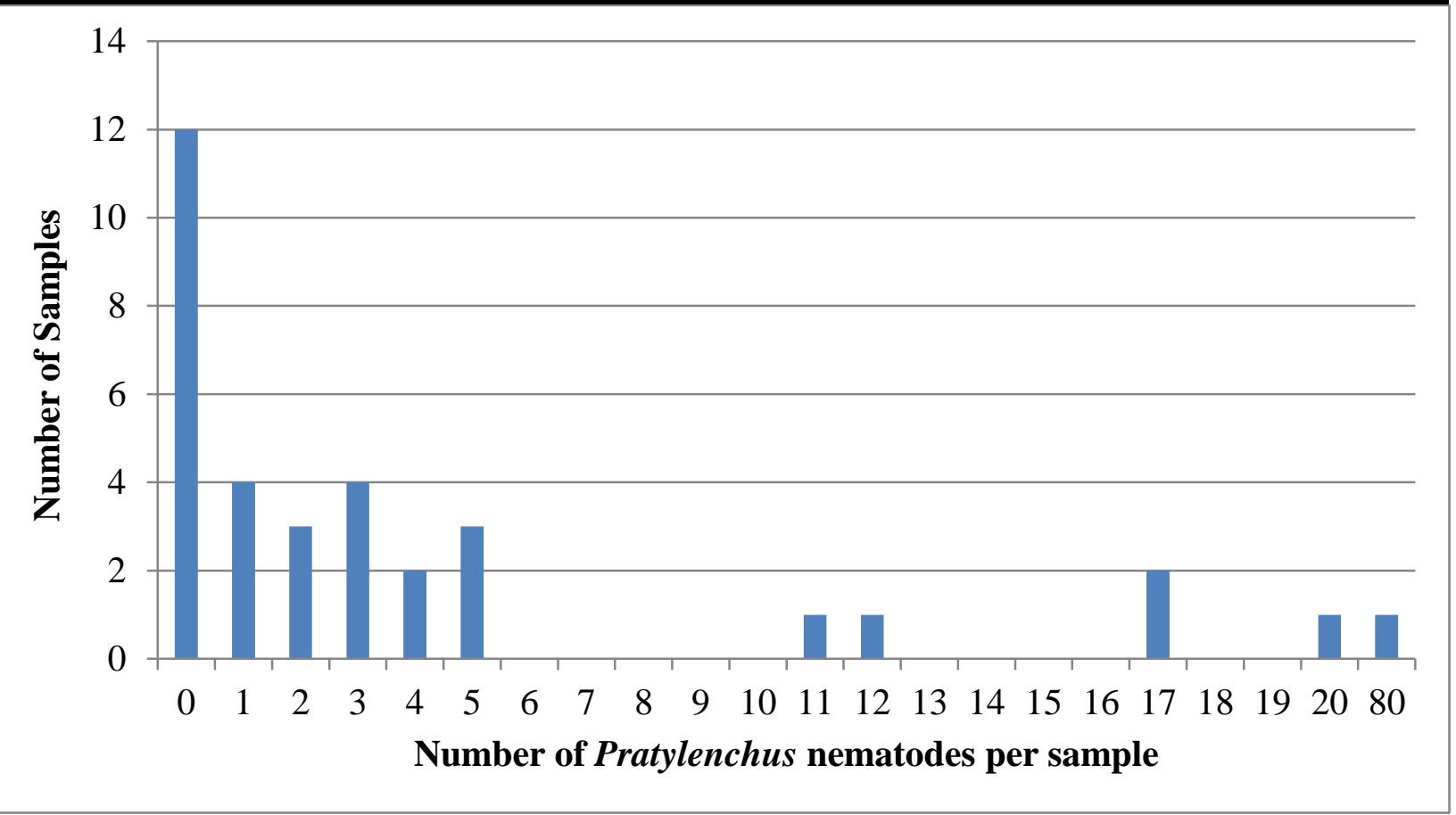

Table 5.1. Frequency of Pasteuria endospores attached to Pratylenchus recovered from $100-\mathrm{cm}^{3}$ soil or from 1-gram Zea mays roots or Phaseolus vulgaris roots for six samples collected from certified organic farms in the Mid-Atlantic states.

\begin{tabular}{lcccc}
\hline $\begin{array}{l}\text { Sample } \\
\text { ID }\end{array}$ & Specimen & No. of Pasteuria & $\begin{array}{c}\text { Species of nematode } \\
\text { specimen (if known) }\end{array}$ & $\begin{array}{c}\text { Source of } \\
\text { specimen }\end{array}$ \\
\hline
\end{tabular}

Survey of Pasteuria on Pratylenchus in organic farm soils:

\begin{tabular}{lllll}
\hline MD2B & 1 & 10 & Pr. crenatus & Soil \\
\hline PA11B & 1 & 1 & Pr. crenatus & Soil \\
& 2 & 1 & Pr. crenatus & Soil \\
& 3 & 1 & Pr. crenatus & Soil \\
\hline PA15C & 1 & 2 & Pr. crenatus & Soil \\
\hline PA16 & 1 & 1 & Pr. crenatus & Soil \\
& 2 & 2 & Pr. crenatus & Soil \\
\hline PA17A & 1 & 1 & Pr. crenatus & Soil \\
\hline
\end{tabular}

Baiting trial to increase detection of Pasteuria:

\begin{tabular}{lllll} 
PA17A & 2 & 1 & Pratylenchus $\mathrm{sp}$. & Corn roots \\
\hline MD2A & 1 & 1 & Pr. crenatus & Corn roots \\
& 2 & 1 & Pr. crenatus & Corn roots \\
& 3 & 2 & Pr. crenatus & Corn roots \\
& 4 & 2 & Pratylenchus juvenile & Corn roots \\
& 5 & 1 & Pratylenchus juvenile & Bean roots \\
& 6 & 1 & Pratylenchus juvenile & Bean roots \\
\hline \hline
\end{tabular}


Table 5.2. Proportion of Pratylenchus with and without Pasteuria recovered from $100-\mathrm{cm}^{3}$ soil or from 1-gram Zea mays roots or Phaseolus vulgaris roots for six samples collected from certified organic farms in the Mid-Atlantic states.

\begin{tabular}{|c|c|c|c|c|c|}
\hline $\begin{array}{l}\text { Sample } \\
\text { ID }\end{array}$ & $\begin{array}{l}\text { No. of lesion } \\
\text { nematodes } \\
\text { recovered } *\end{array}$ & $\begin{array}{l}\text { No. of lesion } \\
\text { nematodes } \\
\text { observed }\end{array}$ & $\begin{array}{l}\text { No. of observed } \\
\text { lesion nematodes } \\
\text { with Pasteuria }\end{array}$ & $\begin{array}{l}\text { Proportion of } \\
\text { lesion nematodes } \\
\text { with Pasteuria }\end{array}$ & \\
\hline
\end{tabular}

Survey of Pasteuria on Pratylenchus in organic farm soils:

\begin{tabular}{lrrrrr}
\hline MD2B & 5 & 5 & 1 & $20.0 \%$ & Soil \\
PA11B & 4 & 4 & 3 & $75.0 \%$ & Soil \\
PA15C & 2 & 2 & 1 & $50.0 \%$ & Soil \\
PA16 & 20 & 10 & 2 & $20.0 \%$ & Soil \\
PA17A & 5 & 5 & 1 & $20.0 \%$ & Soil \\
MD2A & 4 & 4 & 0 & $0.0 \%$ & Soil
\end{tabular}

Baiting trial to increase detection of Pasteuria:

\begin{tabular}{lrrrrl}
\hline PA17A & 4 & 4 & 2 & $50.0 \%$ & Corn roots \\
MD2A & 40 & 40 & 4 & $10.0 \%$ & Corn roots \\
MD2A & 16 & 16 & 2 & $12.5 \%$ & Bean roots \\
\hline
\end{tabular}

* Total number lesion nematodes recovered for sample PA16 is extrapolated from a partial sample count.

Table 5.3. Mean population density of Pratylenchus recovered from certified organic farm soils in the Mid-Atlantic states.

\begin{tabular}{lcc} 
& No. Pratylenchus $/ 100 \mathrm{~cm}^{3}$ soil & No. of Samples \\
\hline Samples without Pasteuria on Pratylenchus & $10.1 \pm 4.9$ & 16 \\
Samples with Pasteuria on Pratylenchus & $6.7 \pm 2.7$ & 6 \\
\hline
\end{tabular}

* Mean \pm standard error.

Table 5.4. Correlation coefficients of soil parameters measured for 16 of 22 samples in which Pratylenchus was detected in a survey of organic soils from five Mid-Atlantic states. Pasteuria was not detected on Pratylenchus in these samples.

\begin{tabular}{llllllll}
\hline & Pratylenchus & $\mathrm{pH}$ & $\mathrm{CEC}$ & $\mathrm{P}_{2} \mathrm{O}_{5}$ & $\mathrm{~K}$ & $\mathrm{Ca}$ & $\mathrm{Mg}$ \\
\hline Pratylenchus & 1.00 & & & & & & \\
$\mathrm{pH}$ & 0.56 & 1.00 & & & & & \\
$\mathrm{CEC}$ & 0.38 & $\mathrm{~ns}$ & 1.00 & & & & \\
$\mathrm{P}_{2} \mathrm{O}_{5}$ & 0.35 & $\mathrm{~ns}$ & 0.57 & 1.00 & & & \\
$\mathrm{~K}$ & $\mathrm{~ns}$ & $\mathrm{~ns}$ & 0.56 & 0.47 & 1.00 & & \\
$\mathrm{Ca}$ & 0.47 & 0.46 & 0.96 & 0.54 & 0.43 & 1.00 & \\
$\mathrm{Mg}$ & $\mathrm{ns}$ & $\mathrm{ns}$ & 0.79 & 0.59 & 0.71 & 0.72 & 1.00 \\
\hline
\end{tabular}

* soil $\mathrm{pH}(\mathrm{pH})$, cation exchange capacity meq/100g (CEC), and pounds per acre of available phosphorus pentoxide $\left(\mathrm{P}_{2} \mathrm{O}_{5}\right)$, potassium $(\mathrm{K})$, calcium $(\mathrm{Ca})$, and magnesium $(\mathrm{Mg})$. 
Table 5.5. Correlation coefficients of soil parameters measured for 6 of 22 samples in which Pasteuria was detected on Pratylenchus in a survey of organic soils from five Mid-Atlantic states.

\begin{tabular}{|c|c|c|c|c|c|c|c|c|}
\hline & Pratylenchus & $\begin{array}{l}\text { Pratylench } \\
\text { Pasteuria }\end{array}$ & ${ }_{\mathrm{pH}}^{+}$ & CEC & $\underline{\mathrm{P}}_{2} \underline{\mathrm{O}}_{5}$ & K & $\mathrm{Ca}$ & $\mathrm{Mg}$ \\
\hline Pratylenchus & 1.00 & & & & & & & \\
\hline Pratylenchus + Pasteuria & ns & 1.00 & & & & & & \\
\hline $\mathrm{pH}$ & -0.83 & -0.39 & 1.00 & & & & & \\
\hline CEC & $\mathrm{ns}$ & $\mathrm{ns}$ & 0.36 & 1.00 & & & & \\
\hline $\mathrm{P}_{2} \mathrm{O}_{5}$ & -0.67 & 0.37 & 0.57 & $\mathrm{~ns}$ & 1.00 & & & \\
\hline $\mathrm{K}$ & ns & ns & ns & 0.64 & ns & 1.00 & & \\
\hline $\mathrm{Ca}$ & -0.57 & -0.40 & 0.79 & 0.83 & ns & 0.62 & 1.00 & \\
\hline $\mathrm{Mg}$ & 0.41 & ns & ns & 0.32 & $\mathrm{~ns}$ & -0.43 & ns & 1.00 \\
\hline
\end{tabular}

* soil $\mathrm{pH}(\mathrm{pH})$, cation exchange capacity meq/100g (CEC), and pounds per acre of available phosphorus pentoxide $\left(\mathrm{P}_{2} \mathrm{O}_{5}\right)$, potassium $(\mathrm{K})$, calcium $(\mathrm{Ca})$, and magnesium $(\mathrm{Mg})$.

\subsection{Increasing detection of Pasteuria}

Pasteuria were detected on Pratylenchus recovered from plant roots for samples MD2A and PA17A (Table 5.1 and Table 5.2). The calculated number of lesion nematodes per green bean plant ranged from two to 30.6 individuals, with an average of 15.5 nematodes in five samples. Average lesion nematode density on corn was 154.7, with the number of individuals per sample ranging from zero to 452.8 for six samples. The green bean planted for sample PA17A died, so data are not available for this treatment.

\subsection{Reproduction of Pr. penetrans in four soil treatments}

The number of lesion nematodes recovered from treatments ranged from none to 467 per gram root (Figure 5.3). Differences between container types were not significant, so data were combined to test for effects of the four soil treatments. The number of Pratylenchus nematodes differed significantly $(\mathrm{P}=0.001)$ among soil treatments. Paired contrasts (Table 5.6) indicated that higher lesion nematode densities were present in uninoculated soil treatments than in the sterile or non-sterile soil treatments that were inoculated with $P r$. penetrans. Indigenous $P r$. 
crenatus were recovered from uninoculated soils and may have been the source of high lesion nematode populations.

Pasteuria endospores were observed on Pr. crenatus nematodes in one uninoculated control sample from a 250- $\mathrm{cm}^{3}$ glass beaker. Mononchus and Helicotylenchus were observed in one non-sterile treatment and Pasteuria endospores were found in the latter.

Figure 5.3. Means and standard error for the total number of lesion nematodes per 1-gram root from green bean (Phaseolus vulgaris) cv. Jade in four soil treatments.

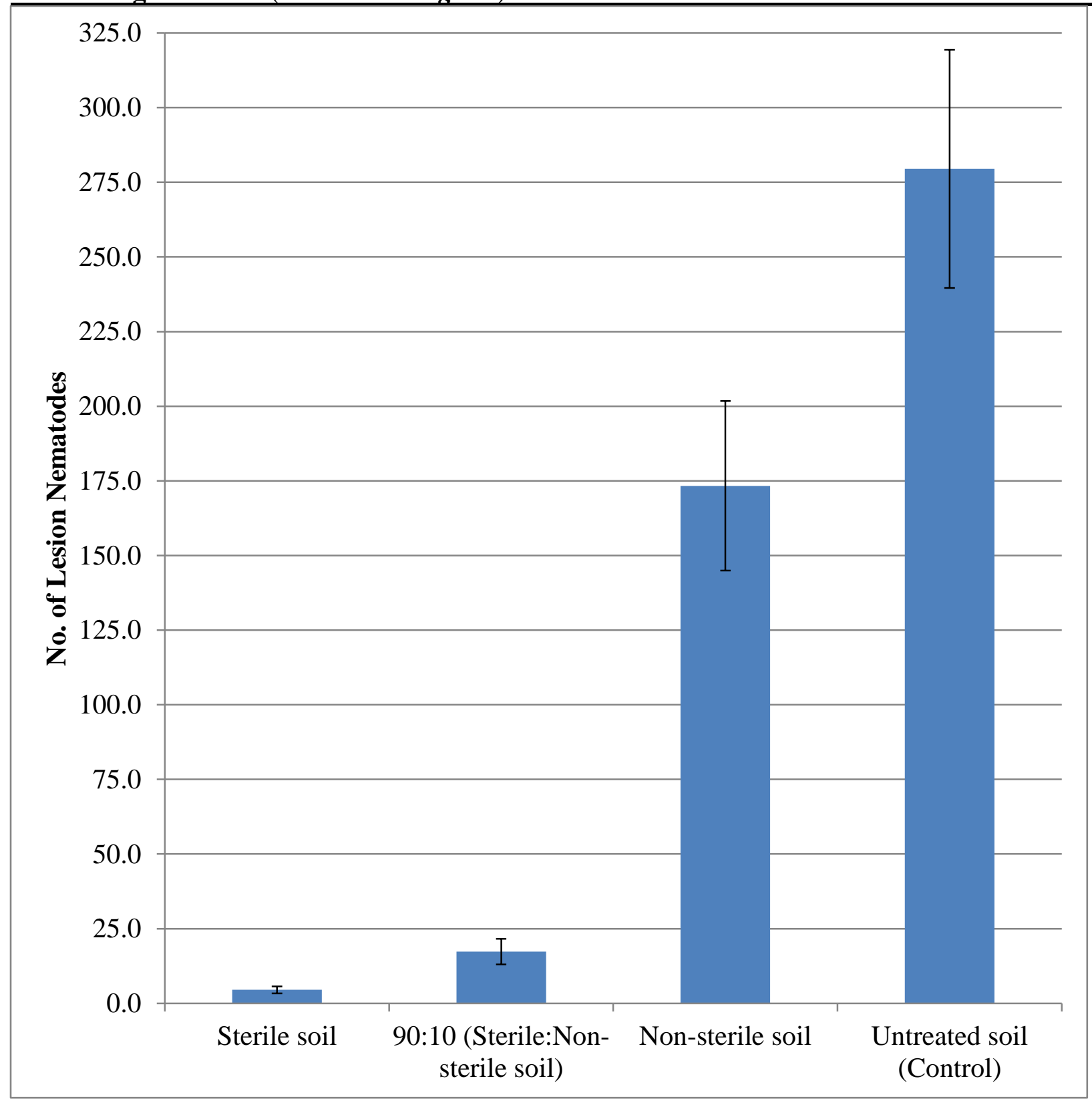


Table 5.6. Paired contrasts of mean number of lesion nematodes recovered per gram root from green bean (Phaseolus vulgaris) cv. Jade in four soil treatments.

\begin{tabular}{lclc}
\hline & Non-sterile soil & Sterile soil & $90: 10$ Sterile:non-sterile soil \\
\hline Untreated soil (Control) & $\mathrm{P}=0.006$ & $\mathrm{P}<0.0001$ & $\mathrm{P}<0.0001$ \\
Non-sterile soil & - & $\mathrm{P}<0.0001$ & $\mathrm{P}<0.0002$ \\
Sterile soil & - & - & ns \\
\hline
\end{tabular}

\subsection{Reproduction of Pr. penetrans in soils with and without Pasteuria}

Soils that were not inoculated with Pr. penetrans had negligible recovery of lesion nematodes. Due to zero counts attributed to uninoculated treatments, data were log transformed $\left(\log _{10}[\mathrm{x}+1]\right)$ to normalize the distribution. There were no significant differences between fresh and dry shoot weights of the bean plants at the 8-week harvest. Population densities of Pr. penetrans also did not differ significantly among soil types.

The presence or absence of Pasteuria endospores $(\mathrm{P}=0.03)$ and time of harvest $(P=0.0006)$ significantly affected the number of lesion nematodes extracted (Table 5.7). Population densities were greater in pots where Pratylenchus inoculum was added, as expected, but did not differ significantly among other factors. Paired contrasts between soils in which Pasteuria were and were not previously detected on lesion nematodes and the time of harvest indicated that populations of Pr. penetrans decreased between the 2-week and 8-week harvest regardless of treatment (Table 5.8 and Figure 5.4). The mean population density in soils without Pasteuria was higher than in soils with Pasteuria at the 2-week harvest but this difference was not significant. At the 8-week harvest, nematode populations in soils without Pasteuria were significantly greater than in soils with Pasteuria $(\mathrm{P}=0.09)$.

When included as a covariate in the statistical model, the effect of soil $\mathrm{pH}$ on lesion nematode densities was statistically significant, but the effect of Pasteuria remained significant (Table 5.9). Lesion nematode densities were higher in soils with higher $\mathrm{pH}$. The average soil $\mathrm{pH}$ 
for the 12 soils was 6.5 , and differences between $\mathrm{pH}$ levels within each soil pair ranged from 0 to 0.5 (Table 4.2).

Pasteuria endospores were detected on three lesion nematodes, each from different samples. One nematode was identified as Pr. penetrans and the other two nematode individuals could not be identified. The endospore-attached Pr. penetrans was recovered from Sample PA12, and Pasteuria had not been detected in these soils. The unidentified lesion nematodes were recovered from Sample MD2B and PA15C. Endospore-attached nematodes were only detected in samples from the 2-week harvest.

Table 5.7. Analysis of variance of treatment effects on the number of lesion nematodes recovered per plant from different soil types with and without Pasteuria endospores.

\begin{tabular}{lrrrr}
\hline Source & DF & Sum of Squares & F Ratio & \multicolumn{1}{c}{ P > F } \\
Pasteuria & 1 & 0.715434 & 4.7811 & 0.0313 \\
Harvest & 1 & 1.883756 & 12.5888 & 0.0006 \\
Pr. penetrans & 1 & 45.057656 & 301.1119 & $<0.0001$ \\
Soil type & 5 & 0.562728 & 0.7521 & 0.5866 \\
Block & 2 & 0.445268 & 1.4878 & 0.2311 \\
Pasteuria * Harvest & 1 & 0.007367 & 0.0492 & 0.8249 \\
Pasteuria * Pr. penetrans & 1 & 0.231201 & 1.5451 & 0.2170 \\
Pasteuria * Soil type & 5 & 0.868095 & 1.1603 & 0.3346 \\
Harvest * Pr. penetrans & 1 & 1.657656 & 11.0778 & 0.0012 \\
Harvest * Soil type & 5 & 0.132490 & 0.1771 & 0.9706 \\
Pr. penetrans * Soil type & 5 & 0.777273 & 1.0389 & 0.3995 \\
Pasteuria * Harvest * Pr. penetrans & 1 & 0.038351 & 0.2563 & 0.6139 \\
Pasteuria * Harvest * Soil type & 5 & 0.822695 & 1.0996 & 0.3660 \\
Pasteuria * Pr. penetrans * Soil type & 5 & 1.059712 & 1.4164 & 0.2255 \\
Harvest * Pr. penetrans * Soil type & 5 & 0.479773 & 0.6412 & 0.6688 \\
Pasteuria * Harvest * Pr. penetrans * Soil type & 5 & 1.005495 & 1.3439 & 0.2527 \\
Error & 94 & 14.065932 & & \\
\hline
\end{tabular}

Table 5.8. Paired contrasts of mean number of lesion nematodes recovered from soils at 2 and 8 weeks after inoculation in soil treatments with or without Pasteuria endospores.

\begin{tabular}{lc}
\hline Paired contrast & Significance (P-value) \\
\hline 2-week X 8-week, Pasteuria present & $\mathrm{P}=0.01$ \\
2-week X 8-week, Pasteuria absent & $\mathrm{P}=0.02$ \\
Pasteuria present X Pasteuria absent, 2-week & $\mathrm{P}=0.17$ \\
Pasteuria present X Pasteuria absent, 8-week & $\mathrm{P}=0.09$ \\
\hline
\end{tabular}


Table 5.9. Analysis of variance of treatment effects of soil pH on the number of lesion nematodes recovered from soils with and without Pasteuria endospores.

\begin{tabular}{lrrrr}
\hline Source & DF & Sum of Squares & F Ratio & P > F \\
\hline Pasteuria & 1 & 0.574766 & 3.9881 & 0.0479 \\
Harvest & 1 & 1.883756 & 13.0707 & 0.0004 \\
Pr. penetrans & 1 & 45.057656 & 312.6391 & $<0.0001$ \\
Block & 2 & 0.445268 & 1.5448 & 0.2172 \\
Pasteuria * Harvest & 1 & 0.007367 & 0.0511 & 0.8215 \\
Pasteuria * Pr. penetrans & 1 & 0.231201 & 1.6042 & 0.2075 \\
Harvest * Pr. penetrans & 1 & 1.657656 & 11.5019 & 0.0009 \\
Pasteuria * Harvest * Pr. penetrans & 1 & 0.038351 & 0.2661 & 0.6068 \\
Soil pH & 1 & 0.606188 & 4.2061 & 0.0422 \\
Error & 133 & 19.168005 & & \\
\hline \hline
\end{tabular}

Figure 5.4. The mean number of lesion nematodes recovered at 2 and 8 weeks after inoculation in soil treatments with or without Pasteuria endospores.

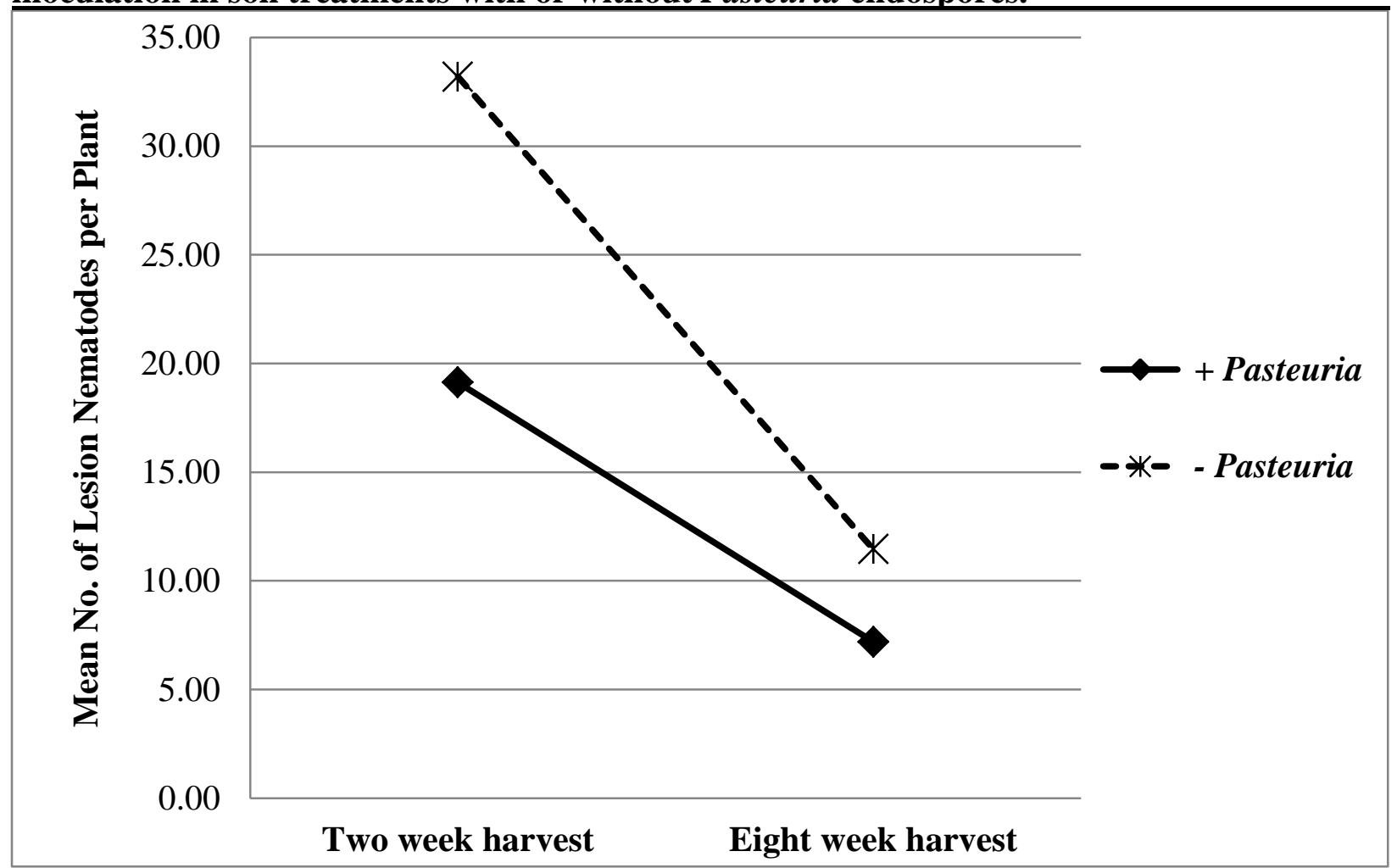

*Data are back transformed.

\subsection{DISCUSSION}

6.1 Survey of Pasteuria on Pratylenchus in certified organic cropping soils 
Lesion nematodes were detected in $65 \%$ of soil samples collected from certified organic farms in the Mid-Atlantic United States. Endospores of Pasteuria were detected on Pratylenchus crenatus in $27 \%$ of samples in which lesion nematodes were observed. The mean population density of Pratylenchus in these soils was lower than in soils without Pasteuria on lesion nematodes. The damage threshold for Pratylenchus ranges from 50 to 1800 nematodes per $100 \mathrm{~cm}^{3}$ soil (Potter and Olthoff, 1993). Lesion nematode density was above the damage threshold in only one of the samples in which Pratylenchus occurred (PA14), and Pasteuria endospores were not detected in that sample. There were no clear indicators from the survey questionnaire or other analyses to explain the high densities observed in this sample compared to other samples.

Densities of Pratylenchus nematodes and Pasteuria reflect pre-season sampling used for this survey. Under ideal conditions, a survey of this nature would be based on post-season sampling as this is the time of year when lesion nematodes move out of plant roots and into surrounding soil. Densities of plant-parasitic nematodes tend to be lower in soils sampled prior to the crop-growing season compared to soils sampled near the end of the season (Bhan et al., 2010). It is possible that populations of lesion nematodes and, therefore, Pasteuria were below detection levels in some samples.

Kariuki and Dickson (2007) presented evidence that $P$ a. penetrans may be more readily detected from spring sampling because endospores are released from Meloidogyne cadavers after roots decay over the winter. Given that endospore-attached Pratylenchus were recovered from roots in the assays described in this report, endospore-filled lesion nematode cadavers may be present within plant roots. 
Sample PA12 was used in the experiment to compare reproduction of Pr.penetrans in soils with and without Pasteuria. Although Pasteuria was not detected on the three Pr. crenatus recovered from the initial soil assay, Pasteuria was observed on a single Pr.penetrans recovered from a treatment that had been inoculated with Pr. penetrans. Occurrence of Pasteuria in this sample was not included in the survey results because it was detected as a result of incidental baiting. It is likely that a greater number of soils collected contained Pasteuria than were identified from soil extractions. Future surveys should bait all soils with target host nematodes to more accurately determine distribution and frequency of Pasteuria.

Kotcon (1990) collected 205 soil samples for a survey of plant-parasitic nematodes in West Virginia peach orchards between late March and early May 1986. Species of Pratylenchus were observed in $77 \%$ of the samples and the mean population density was $8.4 \pm 0.7$ lesion nematodes per $100 \mathrm{~cm}^{3}$ soil. In a survey of plant-parasitic nematodes sampled from wheat and barley soils in early spring, Hollaway et al. (2008) detected lesion nematodes in 53\% of samples and reported a median density of 9 nematodes per gram dry root. These results are similar to those found in this survey and show a similar pattern in frequency and distribution of lesion nematodes sampled in the spring. Pratylenchus occurred more frequently than all other plantparasitic nematodes in assays from organic vegetable and cereal crop production soils in Germany (Hallman et al., 2007). These researchers collected both pre- and post-season soils, but results were not delineated based on the time of sampling.

The occurrence of Pasteuria on plant parasitic nematodes in Florida was reported by Hewlett et al. (1994). Pasteuria endospores were observed on nematodes recovered from soil and root samples that were assayed by the Florida Cooperative Extension Service from 1992 through 1993 and the Florida Department of Agriculture and Consumer Services, Division of 
Plant Industry from 1990 through 1993. Pasteuria endospores were detected in 14 plant parasitic nematode genera collected from 41 Florida counties. Pasteuria endospores were reported on Pratylenchus in 21 of the 335 samples in which Pasteuria were observed on plant parasitic nematodes. Authors noted that samples submitted for these soil analyses did not represent an even distribution of soils in Florida. In this survey of certified organic cropping soils, additional plant parasitic nematodes were not targeted for analyses and observations of Pasteuria endospores on Helicotylenchus and Hoplolaimus were incidental.

Of the lesion nematodes with Pasteuria endospores attached, the number of endospores per nematode ranged from 1 to 10, with 1 to 2 endospores attached to 14 out of 15 specimens. In a survey of 73 samples collected from turf grass, 1 to 5 endospores of Pasteuria were attached to $64 \%, 66 \%, 70 \%, 78 \%$, and $70 \%$ of B. longicaudatus, H. galeatus, H. microlobus, T. annulatus, and Meloidogyne specimens, respectively (Giblin-Davis et al., 1990). The total number of specimens observed for each genus ranged from 41 to 181 , which supports recommendations to collect a greater number of samples for future surveys of Pasteuria on Pratylenchus.

Lesion nematode density was positively correlated with soil $\mathrm{pH}$, calcium content, and cation exchange capacity in the 16 samples where Pasteuria was absent. In contrast, density of Pratylenchus was negatively correlated with soil $\mathrm{pH}$, calcium, and phosphorus content in the six soils where Pasteuria was detected. These correlations could imply density dependent parasitism, and Pasteuria may have a greater effect on lesion nematode populations in soils that are conducive to Pratylenchus. These soil variables may affect the interaction between Pasteuria and Pratylenchus species; however, observed correlations could be a result of a statistical fluke since one or two outliers could have a disproportionate effect on correlations. The small sample size in this survey warrants additional studies to validate these findings. 
Investigations of interactions between Pasteuria and physiochemical soil properties have been conducted previously (Afolabi et al., 1995; Mateille et al., 2002; Dabiré and Mateille, 2004; Dabiré et al., 2007). Soil texture and porosity appear to affect incidence of Pasteuria on plantparasitic nematodes. In this study, soil type was not a significant factor influencing density of Pratylenchus. Soil textures in the survey samples ranged from fine to fine-loamy, fine-silty, and loamy-skeletal. Given the limited variation in type of soils sampled for this survey, it is not surprising that soil type was not correlated with differences in lesion nematode density in soils with or without Pasteuria. The majority of soils sampled for the survey had been carefully managed for organic crop production for several years. Ninety-two percent of the farm managers surveyed indicated use of high diversity crop rotation, $88 \%$ used green manure and cover crops, $80 \%$ used noncommercial manure, $64 \%$ used compost and/or compost extracts, and $52 \%$ used summer fallow to manage their crop growing soils.

Lesion nematode densities in soils with Pasteuria were negatively correlated with soil $\mathrm{pH}$, with the mean $\mathrm{pH}$ being 6.5 in all data sets. Given the low number of survey samples, possible effects of soil $\mathrm{pH}$ on the interactions of Pasteuria and lesion nematodes cannot be deduced from these data. Nonetheless, Afolabi et al. (1995) measured the electrostatic potential $(\mathrm{mV})$ of Pasteuria penetrans endospores at soil $\mathrm{pH}$ levels of 3, 7 and 9 in the presence of three different concentrations of lanthanum $\left(\mathrm{La}^{3+}\right)$, calcium $\left(\mathrm{Ca}^{2+}\right)$ and potassium $\left(\mathrm{K}^{+}\right)$. Endospores had the highest net negative charge at $\mathrm{pH} 7$ with a potassium concentration of $10^{-5} \mathrm{~mol}^{-1}$. The electrostatic potential decreased as acidity or alkalinity increased. It also decreased at higher salt concentrations and cation valency. These authors indicated that endospore attachment to the nematode cuticle may be affected by electrolyte concentration and $\mathrm{pH}$. 
Chen et al. (1994) indicated a possible correlation between levels of inorganic nitrogen and density of Pa. penetrans infecting Meloidogyne. Densities of endospore-attached juveniles and infected females recovered from tobacco roots and field soils were higher in treatments amended with $158 \mathrm{~kg}$ ammonium nitrate/ha compared to those amended with $89 \mathrm{~kg}$ ammonium nitrate/ha. Analyses of soil organic matter were not conducted for all samples collected for this survey. Future studies should include assessment of nitrogen levels.

Mateille et al. (2002) detected Meloidogyne in $79.6 \%$ of 632 soil samples collected from six countries, and Pa. penetrans endospores were attached to juveniles in $36.8 \%$ of those samples. The proportion of root-knot nematodes with $P$ a. penetrans endospores attached was correlated with soil texture and densities of Meloidogyne. There was a positive linear correlation between Meloidogyne population densities and the proportion of endospore-attached juveniles. A similar trend was observed for soils with higher proportions of fine particles (clay and fine silt). The percentage of root-knot nematodes with Pa. penetrans decreased as the percent of coarse and fine sand particles increased. Soil textures for samples with Pa. penetrans varied from 1.5 to $30.2 \%$ clay and fine silt, and 30.1 to $91.2 \%$ fine and coarse sand. These authors did not indicate correlations between occurrence of Pa. penetrans on Meloidogyne and mean soil $\mathrm{pH}$, which ranged from 6.3 to 7.3 .

This study provides a baseline from which further investigations of Pasteuria as biological control agents of lesion nematodes in organic cropping systems may be conducted. The study would have benefited from collecting soil samples over a broader sampling area, increasing the number of samples collected, and sampling at the end of the growing season. Future researchers could conduct an initial assessment from a smaller volume of soil, such as a 1-liter sample instead of 19-liters, and then return to sites of interest to collect additional soil 
needed to conduct experiments. Direct assessment of soil type in addition to using the USDA Natural Resources Conservation Service Web Soil Survey would provide a basis for a more detailed analysis.

Areas of further research include comparisons of density of Pasteuria on plant-parasitic nematodes collected from non-cultivated and cultivated (organic and conventional) soils. A longterm field experiment could be conducted to compare effects of different soil $\mathrm{pH}$ levels on the occurrence of Pasteuria on host nematodes in Pasteuria-infested soils. Experiments of this nature have not been conducted on Pratylenchus. The distribution and frequency of Pasteuria on lesion nematodes in many economically important crop-growing areas has not been reported. There is a critical need to assess occurrence of these organisms, and future surveys should target cropping systems with known susceptibility to Pratylenchus.

\subsection{Increasing detection of Pasteuria}

Populations of Pasteuria have been augmented on host nematodes in field soils and greenhouse pot cultures as described above (Section 2.1.4). Soils were selected based on the hypothesis that Pasteuria was present but had not been observed due to low recovery of lesion nematodes from samples. Pasteuria was previously detected on lesion nematodes recovered from samples collected from the same farm. In this test, Pasteuria endospores were observed on lesion nematodes recovered from roots for Sample MD2A. The MD2A soil sample was collected from a cropping area adjacent to the site where MD2B soils were collected and where Pasteuria was previously detected on Pr. crenatus. Sample MD2A was the only soil in which Pasteuria was detected on lesion nematodes as a result of this baiting test. Presence of Pasteuria on lesion nematodes was confirmed for Sample PA17A. 
Lesion nematodes were extracted from plant roots but not from rhizosphere soil. In natural conditions, endospore attachment is known to occur only in the soil matrix; although, Mankau and Imbriani (1975) suggested endospore attachment could occur within a plant root. Pasteuria endospores remain attached after the nematode enters a plant root, and endosporeattached nematodes could have migrated out of roots during extraction. Hewlett and Dickson (1993) induced attachment of Pasteuria endospores to nematodes by centrifugation of nematodes in a suspension of endospores. It is possible that endospores were released from nematode cadavers during shaker extraction and may have attached to other nematodes in the suspension of water and roots.

Recovery of endospore-attached nematodes from roots may suggest that cadavers degrade inside roots and release endospores that attach to lesion nematodes migrating out of roots after hatching. Alternatively, nematodes may have acquired endospores while migrating through soil, entered the roots, and re-emerged with the endospore still attached before the Pasteuria fully colonized the host nematode. Either explanation may be worth investigating to determine if endospore-infested roots may be cultivated as a source of in vivo inocula for Pasteuria species infecting vermiform endoparasites, such as Pratylenchus.

\subsection{Reproduction of Pr. penetrans in four soil treatments}

This experiment was conducted to determine if the nature of lesion nematode suppression in the WVU Organic Farm soils is general or specific. The expected outcome was that lesion nematode reproduction would be lowest in the non-sterile field soils compared to the sterilized soil and that suppressiveness would re-establish in the 90:10 sterile:non-sterile treatment.

The population density decrease in the sterile and 90:10 sterile:non-sterile soil treatments compared to a $50 \%$ population density increase in the non-sterile soil treatment indicated that 
either sterilization of the field soil was deleterious to nematode reproduction, or indigenous nematode inoculum overwhelmed the Pr. penetrans inoculum added to the sterile and non-sterile soil treatments. Pratylenchus penetrans were recovered from all four treatments and Pr.crenatus were recovered from all treatments except for the sterile soils.

Nematode density in the uninoculated control treatment was significantly higher than in all other treatments. Due to a misunderstanding, this treatment was added to the bench 4 weeks after the three experimental treatments. Plants were allowed to grow for an 8-week period, and during the last 4 weeks of growth, these containers did not have other plants to compete with on the lab bench. It is likely that observed outcomes from the control treatment do not accurately reflect differences between the inoculated and uninoculated treatments.

Treatment effects would have been measured more effectively if data were collected for all response variables, including number of nematodes per $100 \mathrm{~cm}^{3}$ soil and total plant root weight. Analyses of total nematode density per plant, as opposed to density per 1-gram root, would provide stronger evidence to support observed outcomes.

Additionally, results may have been affected by the density of nematode inoculum. Densities of nematodes recovered from WVU greenhouse pot culture were lower than expected. The presence of the predatory nematode Mononchus in the Pratylenchus pot culture may have affected these nematode populations. However, Pr. penetrans often is difficult to maintain in greenhouse pot culture (personal observation).

Mankau (1975) measured effects of Pa. penetrans soil treatments on tomato plants in greenhouse pot culture. Parameters measured were plant height, number of leaves, root-gall rating, and the dry weight of roots and shoots. The soil treatments were (1) air-dried endosporeinfested soil, (2) sterilized endospore-infested soil, and (3) air-dried field soil without 
endospores. Soils were steam sterilized at 15 psi for 1 hour to kill the endospores. For each treatment, four $10-\mathrm{cm}$ plastic pots were filled with soil and a 2-week-old tomato seedling was transplanted into each pot. After 11 days, 10,000 M. incognita J2s were inoculated into each pot and data were collected 70 days after inoculation. Tomato plants grown in air-dried endosporeinfested soil had a significantly higher number of leaves and dry shoot weight compared to the other two soil treatments. The gall rating for plants from endospore-infested soils was 8.5 , which was significantly lower than the rating of 20.5 for sterilized soils and 22.7 for field soils. The results of this experiment indicate that steam-sterilization deactivates endospores, yet effects of steam-sterilization were not significantly different from untreated field soils.

Weibelzahl-Fulton et al. (1996) conducted a greenhouse assay using four soil treatments to determine if suppression of Meloidogyne incognita and M. javanica was caused by $P a$. penetrans. The four soil treatments were: autoclaving, microwaving, air-drying and untreated field soils. The amount of root galls, egg masses, and eggs were significantly lower in the microwaved, air-dried, and untreated soils compared to the autoclaved soils.

Suggestions to improve this assay include recovery of nematodes from soil and root samples, and measuring root and shoot weights. A higher density of Pr. penetrans inoculum would improve detection of differential reproduction of lesion nematodes. Assessment of other biological antagonists present in these soils is also warranted. Future experiments could use alternative soil sterilization methods in conjunction with chloropicrin to eliminate Pasteuria endospores from sterile treatments.

\subsection{Reproduction of Pr. penetrans in soils with and without Pasteuria}

Pasteuria were detected on Pratylenchus species in six soils collected during a survey of certified organic farm soils. These soils were used to compare reproduction of Pratylenchus 
penetrans in soils with and without Pasteuria endospores present. Results of the experiment that compared reproduction of Pr. penetrans in four soil treatments showed that varying levels of background Pratylenchus populations could interfere with treatment effects. To reduce indigenous lesion nematode populations without adversely affecting Pasteuria endospores, the soils used for this experiment were heated in a drying oven at $66 \mathrm{C}$. Results for this experiment indicate that this dry-heat treatment effectively reduced background Pratylenchus populations. Endospore-attached Pratylenchus were recovered at the 2-week harvest and the dry-heat treatment did not appear to hinder Pasteuria endospore attachment. Pratylenchus penetrans were recovered from four samples that were not inoculated with lesion nematodes, and this species was not detected in two of these samples prior to this assay.

Cetintas and Dickson (2004) compared suppression of root-knot nematodes by $P a$. penetrans in four soil treatments. Soils were autoclaved, microwaved, air-dried or untreated. Differences among root galling in treatments that were not inoculated with root-knot nematodes were not significant; however, tomato roots from microwaved soils had higher levels of root galling than roots from the untreated control and autoclaved soil treatments. No root galls were observed on tomato roots from the air-dried soil treatments. Although soil temperatures after microwaving were approximately $75^{\circ} \mathrm{C}$, this treatment did not fully eliminate the background population of root-knot nematodes in these soils. To ensure background nematode populations are eliminated in future assays, soils should incubate for more than 22 hours at a minimum temperature of $75^{\circ} \mathrm{C}$. Soils should also be assayed to determine presence of microbes assumed to be eliminated by heat treatment.

At the 2-week harvest, populations of Pratylenchus penetrans were lower in soils with Pasteuria than without Pasteuria, but differences were not significant. The same trend was 
observed for the 8-week harvest, and these differences were statistically significant. Mankau (1975) reported densities of Pr. scribneri on Phaseolus vulgaris recovered after 55 days were reduced by more than $50 \%$ for soils with $\mathrm{Pa}$. penetrans compared to soils without $\mathrm{Pa}$. penetrans. This finding supports results observed for Pr. penetrans in this experiment.

Endospores have been reported to attach and germinate within 24 hours of nematode exposure to Pasteuria-infested media for juveniles of Meloidogyne, Heterodera and $R$. reniformis (Chen and Dickson, 1998; Bird et al., 2003; Davies, 2009; Hewlett et al., 2010; Schmidt et al., 2010; Davies et al., 2011). Lesion nematodes inoculated into Pasteuria-infested soils may have become infected within the first two weeks after inoculation, making it likely that the level of endospore inoculum in soils with Pasteuria increased during the 8-week growing period.

Studies of suppression of plant parasitic nematodes by Pasteuria have variable results. Cetintas and Dickson (2004) suggested that augmentation of Pa. penetrans would be necessary to maintain suppression of root-knot nematodes in field soils. Some studies show Pa. penetrans is suppressive to root-knot nematodes in long-term cropping systems (Bird and Brisbane, 1988; Chen et al., 1994; Mankau, 1980; Minton and Sayre, 1989). However, Atibalentja et al. (1998) reviewed variable results obtained from multiple studies (Spaull, 1984; Ciancio et al., 1992; Giblin-Davis et al., 1990; Verdejo-Lucas, 1992; Ciancio, 1995). Whether naturally occurring populations of Pasteuria can maintain lesion nematode densities below the damage threshold in cropping soils is unknown. There is a critical need to develop formulations of Pasteuria for use as inundative nematode control.

Plants were harvested at 2 weeks post-inoculation to allow nematode populations to become established in roots but before significant reproduction would occur. Soil factors may 
have caused nematode mortality and reduced the density of nematodes available for extraction at the 2-week harvest. It may be necessary to assess initial population densities at 7 to 10 days postinoculation.

In assays conducted for the survey of organic farm soils, Pasteuria endospores were observed on Pratylenchus crenatus. This was the only lesion nematode species confirmed in four of these six soils. Pasteuria endospores were observed on lesion nematode juveniles and one unidentified Pratylenchus for two soils. In some cases, a species or isolate of Pasteuria parasitizes only one nematode species because of strict host preference for a nematode race and even a single population (Stirling 1985). It is possible that the Pasteuria isolate(s) present in these soils may only parasitize Pr. Crenatus, and infection of the Pr. penetrans inoculum would be negligible.

Pasteuria was observed on a Pr. penetrans specimen recovered from a soil where Pasteuria had not been previously detected. Pasteuria in this sample may have been specific to Pr. penetrans and was not detected due to lack of this lesion nematode species in that soil before inoculation. This observation supports the need to collect soils at the end of the growing season, when Pasteuria endospores are most prevalent and more likely to be detected on host nematodes. Additionally, the soil bioassay method described by Oostendorp et al. (1990) and WeibelzahlFulton et al. (1996) could be used to determine the presence of Pasteuria in soils where it was not previously detected.

Lesion nematode densities, as well as occurrence of Pasteuria on plant-parasitic nematodes, vary with soil type (Norton, 1978; Kotcon, 1990; Afolabi et al., 1995; Mateille et al., 2002; Dabiré and Mateille, 2004; Dabiré et al., 2007). Population densities of Pr. penetrans in soils with or without Pasteuria were not affected by soil type in this experiment. Factors 
discussed in Section 6.1 may be attributed to this observation. The 12 soils assayed had one of four soil textures: four samples were fine textured, five were fine-loamy, one was fine-silty, and two were loamy-skeletal. Effects of soil type may be better assessed by increasing sample size and by confirming soil types through direct assessment as well as the USDA NRCS Web Soil Survey.

This experiment could have been improved by increasing the density of lesion nematodes in the inocula, collecting samples from pre- and post-season soils, and by examining for the presence of Pasteuria endospores on nematodes when fewer than 20 individuals were recovered from soil. Naturally occurring populations of the host nematode and Pasteuria could be augmented by baiting soils as previously described. Endospore-filled lesion nematodes could be recovered from soils using methods described by Oostendorp et al. (1991b). Pasteuria endospores could be collected from infected cadavers and then mixed into soils to increase endospore loads; however, this is a tedious process, especially for small vermiform nematodes such as Pratylenchus.

\subsection{CONCLUSIONS}

Experiments in this study assessed the distribution and frequency of Pasteuria endospores and Pratylenchus nematodes in certified organic cropping soils from the MidAtlantic region of the United States. These soils were used to compare reproduction of $P r$. penetrans in soils with and without Pasteuria endospores, as determined by their presence on lesion nematodes.

Pratylenchus species were present in $65 \%$ of soil samples collected from certified organic farms, and Pasteuria endospores were detected on Pratylenchus crenatus in 27\% of samples in 
which lesion nematodes were observed. Population densities of lesion nematodes were lower in soils with Pasteuria than in soils where Pasteuria had not been detected.

Soils baited with plant host crops to increase detection of Pasteuria resulted in detection of Pasteuria endospores on Pr. crenatus in two soil samples. In one experiment, Pasteuria was observed on Pr. crenatus recovered from untreated WVU Organic Research Farm soils. In another experiment, Pasteuria was detected on Pr. penetrans from a soil sample that had been inoculated with Pr. penetrans. Endospore-attached lesion nematodes were recovered from plant roots for three out of four soils, and Pasteuria had not been previously observed on Pratylenchus from two of these soils.

To the best of the author's knowledge, this is a first report of Pasteuria-like endospores attached to Pratylenchus crenatus from Maryland, Pennsylvania, and West Virginia and to Pratylenchus penetrans from Pennsylvania. Also, endospores characteristic of Pasteuria are reported on Hoplolaimus sp. from Pennsylvania and on Helicotylenchus sp. from Ohio.

An analysis of reproduction of Pr. penetrans on Phaseolus vulgaris cv. Jade in four soil treatments failed to determine if suppression of nematodes in these soils is caused by a biological agent because background indigenous nematode populations obscured results. Two different volumes of soil $\left(400 \mathrm{~cm}^{3}\right.$ and $\left.150 \mathrm{~cm}^{3}\right)$ and two types of planting containers (plastic pot and glass beaker) yielded similar densities of lesion nematodes, indicating equivalent compatibility for nematode reproduction. These findings were used to determine the amount of soil and type of planting container needed to conduct the experiment that compared reproduction of $P r$. penetrans in soils with and without Pasteuria.

In the experiment to evaluate reproduction of Pratylenchus penetrans on Phaseolus vulgaris cv. Jade in soils with and without Pasteuria endospores, populations of Pr. penetrans 
were lower in soils with Pasteuria and differences in final population densities were significant at $\mathrm{P}=0.05$. Results support the hypothesis that the mean rate of increase of Pr. penetrans populations infecting Phaseolus vulgaris cv. Jade will be lower in soils containing Pasteuriaattached Pratylenchus nematodes than in soils where Pasteuria was not detected. When soil pH was included as a covariate in the statistical analyses, densities of Pr. penetrans increased with higher $\mathrm{pH}$ levels; however, the effect of Pasteuria remained significant.

In summary, observations from this research indicate that Pasteuria is present on Pratylenchus in organic cropping soils, indigenous Pasteuria can be baited to increase its detection in soils, endospore attachment can be observed on lesion nematodes recovered from plant root extractions, and reduction of Pr. penetrans populations is greater in soils with Pasteuria than in soils without Pasteuria. Continued research into methods to enhance this biocontrol activity will be needed before Pasteuria will produce reliable lesion nematode control in commercial agriculture. 


\subsection{APPENDIX A}

Host crop history for soils collected from certified organic farms in the Mid-Atlantic states.

$\begin{array}{llll}\text { Sample Date soil Host crop(s) } & \text { Cover crop(s) Rotational crop(s) }\end{array}$

ID collected at sampling Fall 2007/Winter 2008 Summer 2007

Samples with Pratylenchus, with Pasteuria detected on Pratylenchus

$\begin{array}{lllll}\text { MD2A } & 03 / 24 / 2008 & \text { Millet } & \text { Hay, rye } & \text { Grain crops } \\ \text { MD2B } & 03 / 24 / 2008 & \text { Rye-Clover } & \text { Hay, rye } & \text { Grain crops } \\ \text { PA11B } & 04 / 06 / 2008 & \text { Sweet corn } & \text { Vetch, winter rye } & \text { Mixed vegetables } \\ \text { PA15C } & 05 / 14 / 2008 & \text { Garlic } & \text { None } & \text { Mixed vegetables } \\ \text { PA16 } & 05 / 14 / 2008 & \text { Corn } & \text { Wheat } & \text { Mixed vegetables } \\ \text { PA17A } & 04 / 07 / 2008 & \text { Corn } & \text { Varieties unknown } & \text { Mixed vegetables }\end{array}$

Samples with Pratylenchus, without Pasteuria detected on Pratylenchus

$\begin{array}{llllll}\text { MD3A } & 03 / 24 / 2008 & \text { Radish } & \text { Clover, vetch, oats } & & \text { Mixed vegetables } \\ \text { MD3B } & 03 / 24 / 2008 & \text { Brassicas } & \text { Clover, vetch, oats } & & \text { Mixed vegetables } \\ \text { MD22 } & 06 / 06 / 2008 & \text { Potato } & \text { Varieties unknown } & \text { Corn } \\ \text { MD23 } & 06 / 06 / 2008 & \text { Clover, orchard grass } & \text { Oats } & \text { Corn } \\ \text { MD24 } & 06 / 06 / 2008 & \text { Strawberry } & \text { Varieties unknown } & \text { Mixed vegetables } \\ \text { OH5 } & 05 / 15 / 2008 & \text { Green bean } & \text { Varieties unknown } & \text { Mixed vegetables } \\ \text { OH6A } & 05 / 16 / 2008 & \text { None - fallow } & \text { None - fallow } & \text { None - fallow } \\ \text { PA11A } & 04 / 06 / 2008 & \text { Green bean } & \text { Vetch, winter rye } & \text { Mixed vegetables } \\ \text { PA12 } & 04 / 06 / 2008 & \text { Hay } & \text { Hay } & \text { Hay } \\ \text { PA14 } & 04 / 06 / 2008 & \text { Brassicas } & \text { Varieties unknown } & \text { Mixed vegetables } \\ \text { PA15A } & 05 / 14 / 2008 & \text { Garlic } & \text { None } & \text { Mixed vegetables } \\ \text { PA17B } & 04 / 07 / 2008 & \text { Tomato } & \text { Varieties unknown } & \text { Mixed vegetables } \\ \text { PA17C } & 04 / 07 / 2008 & \text { Rye } & \text { Varieties unknown } & \text { Mixed vegetables } \\ \text { PA19 } & 05 / 14 / 2008 & \text { Hay, clover } & \text { Winter wheat } & \text { Hay, clover } \\ \text { PA20B } & 05 / 14 / 2008 & \text { Potato } & \text { Vetch, white clover } & \text { Mixed vegetables } \\ \text { WV25 } & 06 / 06 / 2008 & \text { Pea } & \text { Rye, buckwheat } & \text { Mixed vegetables }\end{array}$

Samples without Pratylenchus

\begin{tabular}{lllll} 
MD1 & $03 / 24 / 2008$ & Tomato & Vetch, rye & Mixed vegetables \\
MD4 & $03 / 24 / 2008$ & Tomato & Vetch & Mixed vegetables \\
MD21 & $06 / 06 / 2008$ & Vetch, orchard grass & Rye & Mixed vegetables \\
OH6B & $05 / 16 / 2008$ & Hay, clover & Hay, clover & Hay, clover \\
OH7 & $05 / 15 / 2008$ & Brassicas & Varieties unknown & Mixed vegetables \\
OH8 & $05 / 15 / 2008$ & Rye & Varieties unknown & Mixed vegetables \\
OH9 & $05 / 15 / 2008$ & Garlic & Winter wheat & Mixed vegetables \\
PA10 & $04 / 07 / 2008$ & Brassicas & Rye, oats, buckwheat & Mixed vegetables \\
PA15B & $05 / 14 / 2008$ & Mixed vegetables & None & Mixed vegetables \\
PA18 & $05 / 14 / 2008$ & Bean, pea, corn & Vetch, rye & Mixed vegetables \\
PA20A & $05 / 14 / 2008$ & Brassicas & Vetch, white clover & Mixed vegetables \\
VA26 & $06 / 07 / 2008$ & Pea & Varieties unknown & Mixed vegetables \\
\hline
\end{tabular}

Mixed vegetables may include the following crops: tomato, corn, peppers, potato, beans, Brassica crops, lettuce, greens, garlic, pea, soybean, cucumber, grains, eggplant, radish, squash. 


\subsection{LITERATURE CITED}

Afolabi, P., Davies, K. G., and O'Shea, P. S. 1995. The electrostatic nature of the spore of Pasteuria penetrans, the bacterial parasite of root-knot nematodes. Journal of Applied Bacteriology 79:244-249. DOI: 10.1111/j.1365-2672.1995.tb03133.x

Anderson, J. M., Preston, J. F., Dickson, D. W., Hewlett, T. E., Williams, N. H., and Maruniak, J. E. 1999. Phylogenetic analysis of Pasteuria penetrans by $16 \mathrm{~S}$ rRNA gene cloning and sequencing. Journal of Nematology 31:319-325.

Anwar, S. A., McKenry, M. V., and Javid, N. 2010. Incidence and population density of plantparasitic nematodes infecting vegetable crops and associated yield losses. Journal of Nematology 42:231.

Atibalentja, N., Noel, G. R., Liao, T. F., and Gertner, G. Z. 1998. Population changes in Heterodera glycines and its bacterial parasite Pasteuria sp. in naturally infested soil. Journal of Nematology 30:81-92.

Atibalentja, N., Jakstys, B. P., and Noel, G. R. 2004a. Life cycle, ultrastructure, and host specificity of the North American isolate of Pasteuria that parasitizes the Soybean Cyst Nematode, Heterodera glycines. Journal of Nematology 36:171-180.

Atibalentja, N., Noel, G. R., and A. Ciancio. 2004b. A simple method for the extraction, PCRamplification, cloning, and sequencing of Pasteuria 16S rDNA from small numbers of endospores. Journal of Nematology 36:100-105.

Atibalentja, N., Noel, G. R., and Domier, L. L. 2000. Phylogenetic position of the North American isolate of Pasteuria that parasitizes the soybean cyst nematode, Heterodera glycines, as inferred from 16S rDNA sequence analysis. International Journal of Systematic and Evolutionary Microbiology 50:605-613. DOI: 10.1099/00207713-50-2-605

Atkins, S. D., Hidalgo-Diaz, L., Kalisz, H., Mauchline, T. H., Hirsch, P. R., and Kerry, B. R. 2003. Development of a new management strategy for the control of root-knot nematodes (Meloidogyne spp.) in organic vegetable production. Pest Management Science 59:183-189. DOI:10.1002/ps.603

Ball-Coelho, B., Bruin, A. J., Roy, R. C., and Riga, E. 2003. Forage pearl millet and marigold as rotation crops for biological control of root-lesion nematodes in potato. Agronomy Journal 95:282-292. DOI:10.2134/agronj2003.2820 
Bao, Y., Vetsch, J., Chen, S., and Randall, G. 2010. Manure and chemical fertilizer effect on soybean cyst nematode, nematode community, and soybean yield in SCN-suppressive and conducive soils. Journal of Nematology 42:232.

Barker, K. R., Pederson, G. A., and Windham, G. L., eds. 1998. Plant and nematode interactions. Agronomy Monograph No. 36. Madison: American Society of Agronomy, Crop Science Society of America, Soil Science Society of America.

Barker, K. R., Townshend, J. L., Bird, G. W., Thomason, I. J., and Dickson, D. W. 1986.

Determining nematode population responses to control agents. Pp. 283-296 in K. D. Hickey, ed. Methods for evaluating pesticides for control of plant pathogens. St. Paul: American Phytopathological Society Press.

Bekal, S., Borneman, J., Springer, M. S., Giblin-Davis, R. M., and Becker, J. O. 2001. Phenotypic and molecular analysis of a Pasteuria strain parasitic to the sting nematode. Journal of Nematology 33:110-115.

Bekal, S., Mankau, R., and Becker, J. O. 2000. Pasteuria penetrans, an infective parasite of rootknot nematodes after 21 years in dry soil. Phytopathology 90:S117 (Abstract).

Bélair, G., Dauphinais, N., Benoit, D. L., and Fournier, Y. 2007. Reproduction of Pratylenchus penetrans on 24 common weeds in potato fields in Québec. Journal of Nematology 39:321-326.

Bélair, G., Dauphinais, N., Fournier, Y., Dangi, O. P., and Clément, M. F. 2005. Effect of forage and grain pearl millet on Pratylenchus penetrans and potato yields in Quebec. Journal of Nematology 37:78-82.

Bélair, G., Fournier, Y., Dauphinais, N., and Dangi, O. P. 2002. Reproduction of Pratylenchus penetrans on various rotation crops in Québec. Phytoprotection 83:111-114. Short communication. DOI: 10.7202/706233ar

Bhan, M., McSorley, R., and Chase, C. A. 2010. Effect of cropping system complexity on plantparasitic nematodes associated with organically grown vegetables in Florida. Nematropica 40:53-70.

Bird, A. F., and Brisbane, P. G. 1988. The influence of Pasteuria penetrans in field soils on the reproduction of root-knot nematodes. Revue de Nèmatologie 11:75-81.

Bird, D. M., and Koltai, H. 2000. Plant parasitic nematodes: Habitats, hormones, and horizontally-acquired genes. Journal of Plant Growth Regulation 19:183-194. 
Bird, D. M., Opperman, C. H., and Davies, K. G. 2003. Interactions between bacteria and plantparasitic nematodes: Now and then. International Journal for Parasitology 33:1269.

DOI: 10.1016/S0020-7519(03)00160-7

Bishop, A. H., Gowen, S. R., Pembroke, B., and Trotter, J. R. 2007. Morphological and molecular characteristics of a new species of Pasteuria parasitic on Meloidogyne ardenensis. Journal of Invertebrate Pathology 96:28-33. DOI: 10.1016/j.jip.2007.02.008

Brown, S. M., and Smart, Jr., G. C. 1984. Attachment of Bacillus penetrans to Meloidogyne incognita. Nematropica 14:171-172.

Castillo, P., and Volvas, N. 2007. Pratylenchus (Nematoda: Pratylenchidae): Diagnosis, biology, pathogenicity and management. The Netherlands: Koninklijke Brill.

DOI: 10.1163/ej.9789004155640.i-523

Cetintas, R., and Dickson, D. W. 2004. Persistence and suppressiveness of Pasteuria penetrans to Meloidogyne arenaria race 1. Journal of Nematology 36:540-549.

Charles, L., Carbone, I., Davies, K. G., Bird, D., Burke, M., Kerry, B. R., and Opperman, C. H. 2005. Phylogenetic analysis of Pasteuria penetrans by use of multiple genetic loci. Journal of Bacteriology 187:5700-5708. DOI:10.1128/JB.187.16.5700-5708

Chen, S., Dickson, D. W., and Whitty, E. B. 1994. Response of Meloidogyne spp. to Pasteuria penetrans, fungi, and cultural practices in tobacco. Supplement to the Journal of Nematology 26:620-625.

Chen, Z. X., and Dickson, D. W. 1998. Review of Pasteuria penetrans: Biology, ecology, and biological control potential. Journal of Nematology 30:313-340.

Chen, Z. X., Dickson, D. W., Mitchell, D. J., McSorley, R., and Hewlett, T. E. 1997. Suppression mechanisms of Meloidogyne arenaria race 1 by Pasteuria penetrans. Journal of Nematology 29:1-8.

Chen, Z. X., Dickson, D. W., and Hewlett, T. E. 1996a. Quantification of endospore concentrations of Pasteuria penetrans in tomato root material. Journal of Nematology 28:50-55.

Chen, Z. X., Dickson, D. W., McSorley, R., Mitchell, D. J., and Hewlett, T. E. 1996b. Suppression of Meloidogyne arenaria race 1 by soil application of endospores of Pasteuria penetrans. Journal of Nematology 28:159-168. 
Ciancio, A. 1995. Phenotypic adaptations in Pasteuria spp. nematode parasites. Journal of Nematology 27:328-338.

Ciancio, A., Mankau, R., and Mundo-Ocampo, M. 1992. Parasitism of Helicotylenchus lobus by Pasteuria penetrans in naturally infested soil. Journal of Nematology 24:29-35.

Cobb, N. A. 1917. A new parasitic nema found infesting cotton and potatoes. Journal of Agricultural Research XI: 27-33.

Cook, J. C., and Baker, K. F. 1983. The nature and practice of biological control of plant pathogens. St. Paul: The American Phytopathological Society.

Corbett, D. C. M. 1970. Root-lesion nematodes (Pratylenchus spp.) in Britain and their identification. Plant Pathology 19:59-64. DOI: 10.1111/j.1365-3059.1970.tb00980.x

Corbett, D. C. M. 1973. Pratylenchus penetrans. Descriptions of plant-parasitic nematodes. St. Albans, UK: Commonwealth Institute of Helminthology.

Coyne, M. S., and Thompson, J. A. 2006. Fundamental soil science. Clifton Park: Thomson Delmar Learning.

Dabiré, R. K., Ndiaye, S., Mounport, D., and Mateille, T. 2007. Relationships between abiotic soil factors and epidemiology of the biocontrol bacterium Pasteuria penetrans in a root-knot nematode Meloidogyne javanica-infested field. Biological Control 40:22-29.

DOI: $10.1016 /$ j.biocontrol.2006.08.001

Dabiré, K. R., and Mateille, T. 2004. Soil texture and irrigation influence the transport and the development of Pasteuria penetrans, a bacterial parasite of root-knot nematodes. Soil Biology and Biochemistry 36:539-543. DOI:10.1016/j.soilbio.2003.10.018

Davies, K. G. 2009. Understanding the interaction between an obligate hyperparasite bacterium, Pasteuria penetrans and its obligate plant-parasitic nematode host, Meloidogyne spp. Advances in Parasitology 68:211-45. DOI: 10.1016/S0065-308X(08)00609-X

Davies, K. G., Rowe, J., Manzanilla-López, R., and Opperman, C. H. 2011. Re-evaluation of the life-cycle of the nematode-parasitic bacterium Pasteuria penetrans in root-knot nematodes, Meloidogyne spp. Nematology 13:825-835. DOI: 10.1163/138855410X552670 
Davies, K. G., Flynn, C. A., Laird, V., and Kerry, B. R. 1990. The life-cycle, population dynamics and host specificity of a parasite of Heterodera avenae, similar to Pasteuria penetrans. Revue de Nématologie 13:303-309.

Davies, K. G., Kerry, B. R., and Flynn, C. A. 1988. Observations on the pathogenicity of Pasteuria penetrans, a parasite of root-knot nematodes. Annals of Applied Biology 112:1491501. DOI: 10.1111/j.1744-7348.1988.tb02086.x

Dickson, D. W., Preston, III, J. F., Giblin-Davis, R. M., Noel, G. R., Ebert, D., and Bird, G. W. 2009. Family Pasteuriaceae Laurent 1890. Pp. 328-347 in: P. De Vos, G. M. Garrity, D. Jones, N. R. Krieg, W. Ludwig, F. A. Rainey, K.-H. Schleifer, and W. B. Whitman, eds. Bergey's manual of systematic bacteriology, The Firmicutes, vol. 3. New York: Springer. DOI: 10.1007/978-0-387-68489-5

Dickson, D. W., Oostengorp, M., and Mitchell, D. J. 1992. Development of Pasteuria penetrans on Meloidogyne arenaria race 1 in the field. Pp. 213-218 in F. J. Gommers and P. W. Th. Maas, eds. Nematology from molecule to ecosystem. Scotland: European Society of Nematologists.

Dong, L. Q., and Zhang, K. Q. 2006. Microbial control of plant-parasitic nematodes: A fiveparty interaction. Plant Soil 288:31-45. DOI 10.1007/s11104-006-9009-3

Dropkin, V. H. 1989. Introduction to plant nematology. Second edition. New York: John Wiley and Sons.

Dutkey, E. M., and Sayre, R. M. 1978. Some factors affecting infection of nematodes by the bacterial spore parasite Bacillus penetrans. Journal of Nematology 10:285.

Ebert, D., Rainey, P., Embley, T. M., and Scholz, D. 1996. Development, life cycle, ultrastructure and phylogenetic position of Pasteuria ramosa Metchnikoff 1888: Rediscovery of an obligate endoparasite of Daphnia magna Straus. Philosophical Transactions of the Royal Society B 351:1689-1701. DOI: 10.1098/rstb.1996.0151

Elekçioğlu, I. H. 1995. Occurrence of Pasteuria bacteria as parasites of plant-parasitic nematodes in the East Mediterranean region of Turkey. Nematologia Mediterranea 23:213-215.

Fademi, O. A., Ogunlade, M. O., Orisajo, S. B., Okeniyi, M. O., Obatolu, B. O., Olatunbosun, O. M., and Jolaoso, A. M. 2010. Protection strategies for "safe cocoa beans harvest" in nematode-infested production environments. Journal of Nematology 42:241. 
Ferris, J. M., and Ferris, V. R. 1998. Biology of plant-parasitic nematodes. Pp. 21-35 in K. R. Barker, G. A. Pederson, and G. L. Windham, eds. Plant and Nematode Interactions. Agronomy monograph No. 36. Madison: American Society of Agronomy, Crop Science Society of America, Soil Science Society of America.

Freitas, L. G., Dickson, D. W., Mitchell, D. J., and Hewlett, T. E. 2000. Infectivity and suppression of Pasteuria penetrans to Meloidogyne arenaria race 1 in tomato following soil fumigation. Nematologica Brasile 24:157-166.

Fritze, D. 2004. Taxonomy of the Genus Bacillus and related genera: The aerobic endosporeforming bacteria. Phytopathology 94:1245-1248. DOI: 10.1094/PHYTO.2004.94.11.1245

Garrity, G. M., Bell, J. A., and Lilburn, T. 2005. The revised road map to the manual. Pp. 159220 in D. J. Brenner, N. R. Krieg, J. T. Staley, and G. M. Garrity, eds. Bergey's Manual of Systematic Bacteriology, 2nd edition, vol. 2, The Proteobacteria, Part A Introductory Essays. New York: Springer. DOI: 10.1007/0-387-28021-9

Giblin-Davis, R. M., McDaniel, L. L., and Bilz, F. G. 1990. Isolates of the Pasteuria penetrans group from phytoparasitic nematodes in bermudagrass turf. Supplement to Journal of Nematology 22:750-762.

Giblin-Davis, R. M., Williams, D. S., Wergin, W. P., Dickson, D. W., Hewlett, T. E., Bekal, S., and Becker, J. O. 2001. Ultrastructure and development of Pasteuria sp. (S-1 strain), an obligate endoparasite of Belonolaimus longicaudatus (Nemata: Tylenchida). Journal of Nematology $33: 227-238$.

Giblin-Davis, R. M., Williams, D. S., Bekal, S., Dickson, D. W., Brito, J. A., Becker, J. O., and Preston, J. F. 2003. 'Candidatus Pasteuria usgae' sp. nov., an obligate endoparasite of the phytoparasitic nematode Belonolaimus longicaudatus. International Journal of Systematic and Evolutionary Microbiology 53:197-200. DOI 10.1099/ijs.0.02292-0

Giblin-Davis, R. M., Nong, G., Preston, J. F., Williams, D. S., Center, B. J., Brito, J. A., and Dickson, D. W. 2011. 'Candidatus Pasteuria aldrichii', an obligate endoparasite of the bacterivorous nematode Bursilla. International Journal of Systematic and Evolutionary Microbiology 61:2073-2080. DOI 10.1099/ijs.0.021287-0

Gonzaga, V., and Santos, J. M. 2009. Detection of Pasteuria thornei in Pratylenchus brachyurus and Pratylenchus zeae. Nematologia Brasileira. 33:103-105. 
Hackenberg, C., Muehlchen, A., Forge, T., and Vrain, T. 2000. Pseudomonas chlororaphis strain Sm3, bacterial antagonist of Pratylenchus penetrans. Journal of Nematology 32:183-189.

Hallmann, J., Frankenberg, A., Paffrath, A., and Schmidt, H. 2007. Occurrence and importance of plant-parasitic nematodes in organic farming in Germany. Nematology 9:869-879.

DOI: $10.1163 / 156854107782331261$

Handoo, Z. A., and Golden, A. M. 1989. A key and diagnostic compendium to the species of the genus Pratylenchus Filipjev, 1936 (lesion nematodes). Journal of Nematology 21:202-218.

Hatz, B., and Dickson, D. W. 1992. Effect of temperature on attachment, development, and interactions of Pasteuria penetrans on Meloidogyne arenaria. Journal of Nematology 24:512521.

Hewlett, T. E., and Dickson, D. W. 1993. A centrifugation method for attaching endospores of Pasteuria spp. to nematodes. Journal of Nematology 25:785-788.

Hewlett, T. E., Stetina, S. R., and Schmidt, L. M. 2010. Rate of germination and growth of in vitro produced Pasteuria spp. parasitizing Rotylenchulus reniformis. Journal of Nematology 42:247.

Hewlett, T., Griswold, S., and Smith, K. 2004. Production of the nematode biological control agent Pasteuria spp. The hard way. Pasteuria Bioscience LLC, Alachua, Florida. 96:1-2.

Hewlett, T. E., Cox, R., Dickson, D. W., and Dunn, R. A. 1994. Occurrence of Pasteuria in Florida. Supplement to Journal of Nematology 26:616-619.

Hollaway, G. J., Vanstone, V. A., Nobbs, J., Smith, J. G., and Brown, J. S. 2008. Pathogenic nematodes of cereal crops in south-west Victoria, Australia. Australasian Plant Pathology 37:505-510. DOI: 10.1071/AP08048

Imbriani, J. L., and Mankau, R. 1977. Ultrastructure of the nematode pathogen, Bacillus penetrans. Journal of Invertebrate Pathology 30:337-347. DOI: 10.1016/0022-2011(77)90143-4

International Federation of Organic Agriculture Movements (IFOAM). 2012. One earth, one future: 2012 Consolidated annual report of the IFOAM action group. Bonn, Germany. Pp. 1-28. www.ifoam.org

Jaffee, B. A., Bastow, J. L., and Strong, D. R. 2007. Suppression of nematodes in a coastal grassland soil. Biology and Fertility of Soils 44:19-26. DOI: 10.1007/s00374-007-0174-1 
Janvier, C., Villeneuve, F., Alabouvette, C., Edel-Hermann, V., Mateille, T., and Steinberg, C. 2007. Review. Soil health through soil disease suppression: Which strategy from descriptors to indicators? Soil Biology and Biochemistry 39:1-23. DOI: 10.1016/j.soilbio.2006.07.001

Jatala, P. 1986. Biological control of plant-parasitic nematodes. Annual Review of Phytopathology 24:453-489. DOI: 10.1146/annurev.py.24.090186.002321

Jenkins, W. R. 1964. A rapid centrifugal-flotation technique for separating nematodes from soil. Plant Disease Reporter 48:692.

Jin, X., Kotcon, J. B., and Morton, J. B. 1991. Interactions between Pratylenchus penetrans and Fusarium avenaceum in red clover. Nematropica 21:105-109.

Johnson, A. W., and Feldmesser, J. 1987. Nematicides - A Historical Review. Pp. 448-454 in J. A. Veech and D. W. Dickson, eds. Vistas on Nematology. Hyattsville: Society of Nematologists.

Kariuki, G. M., and Dickson, D. W. 2007. Transfer and development of Pasteuria penetrans. Journal of Nematology 39:55-61.

Kerr, A. 1982. Biological control of soil-borne microbial pathogens and nematodes. Pp. 429-463 in N. S. Subba Rao, ed. Advances in agricultural microbiology. London: Butterworth Scientific.

Kerry, B. R. 1990. An assessment of progress toward microbial control of plant-parasitic nematodes. Supplement to Journal of Nematology 22:621-631.

Kluepfel, D. A., McInnis, T. M., and Zehr, E. I. 1993. Involvement of root-colonizing bacteria in peach orchard soils suppressive of the nematode Criconemella xenoplax. Phytopathology 83:1240-1245. DOI: 10.1094/Phyto-83-1240

Kotcon, J. B. 1990. Distribution, frequency, and population density of nematodes in West Virginia peach orchards. Supplement to Journal of Nematology 22:712-717.

Kotcon, J. B. 2006. Alternative management systems for plant-parasitic nematodes in horticultural and field crops. West Virginia NE-1019 Annual Report. West Virginia University, Morgantown, West Virginia.

Kotcon, J. B. 2010. West Virginia NE-1040 Annual Report. West Virginia University, Morgantown, West Virginia. 
Kotcon, J. B., Loria, R., and Wixted, D. J. 1987. Pratylenchus penetrans population dynamics on three potato cultivars. Journal of Nematology 19:361-368.

LaMondia, J. A. 2003. Interaction of Pratylenchus penetrans and Rhizoctonia fragariae in strawberry black root rot. Journal of Nematology 35:17-22.

LaMondia, J. A. 2006. Management of lesion nematodes and potato early dying with rotation crops. Journal of Nematology 38:442-448.

Loof, P. A. A. 1961. Tylenchus gulosus Kühn, 1890: Proposed suppression under the plenary powers (Nematoda). Z. N. (S.) 1432. Bulletin of Zoological Nomenclature 18:206-207.

Loof, P. A. A. 1978. The genus Pratylenchus Filipjev, 1936 (Nematoda: Pratylenchidae): A review of its anatomy, morphology, distribution, systematics and identification. Swedish University of Agricultural Sciences. Uppsala: Research Information Centre.

Lotter, D. W. 2003. Organic Agriculture. Journal of Sustainable Agriculture 21:59-128. DOI: 10.1300/J064v1n04_06

Ma, R., Liu, X., Jian, H., and Li, S. 2005. Detection of Hirsutella spp. and Pasteuria sp. parasitizing second-stage juveniles of Heterodera glycines in soybean fields in China. Biological Control 33:223-229. DOI:10.1016/j.biocontrol.2005.03.004

Mai, W. F., Mullin, P. G., Lyon, H. H., and Loeffler, K. 1996. Plant-parasitic nematodes. A pictorial key to genera. New York: Cornell University Press.

Mai, W. F., Bloom, J. R., and Chen, T. A., eds. 1977. Biology and ecology of the plant-parasitic nematode Pratylenchus penetrans. University Park: The Pennsylvania State University College of Agriculture, Agriculture Experimental Station.

Mai, W. F., Crittenden, H. W., and Jenkins, W. R. 1960. Distribution of stylet-bearing nematodes in the northeastern United States. New Brunswick: Rutgers State University.

Mankau, R. 1968. Reduction of root-knot disease with organic amendments under semifield conditions. Plant Disease Reporter 52:315-319.

Mankau, R. 1975. Bacillus penetrans n. comb. causing a virulent disease of plant-parasitic nematodes. Journal of Invertebrate Pathology 26:333-339. DOI: 10.1016/0022-2011(75)90231-1 
Mankau, R. 1980. Biological control of nematode pests by natural enemies. Annual Review of Phytopathology 18:415-40. DOI: 10.1146/annurev.py.18.090180.002215

Mankau, R., and Imbriani, J. 1975. The life cycle of an endoparasite in some tylenchid nematodes. Nematologica 21:89-94. DOI: 10.1163/187529275X00383

Mankau, R., and Prasad, N. 1977. Infectivity of Bacillus penetrans in plant-parasitic nematodes. Journal of Nematology 9:40-45.

Mankau, R., Imbriani, J. L., and Bell, A. H. 1976. SEM Observations on nematode cuticle penetration by Bacillus penetrans. Journal of Nematology 8:179-181.

Mateille, T., Trudgill, D. L., Trivino, C., Bala, G., Sawadogo, A., and Vouyoukalou, E. 2002. Multisite survey of soil interactions with infestation of root-knot nematodes (Meloidogyne spp.) by Pasteuria penetrans. Soil Biology and Biochemistry 34:1417-1424. DOI: 10.1016/S00380717(02)00085-8

McKeen, C. D., and Mountain, W. B. 1960. Synergism between Pratylenchus penetrans (Cobb) and Verticillium albo-atrum R. and B. in eggplant wilt. Canadian Journal of Botany 38:789-794. DOI: $10.1139 / \mathrm{b} 60-068$

Minton, N. A., and Sayre, R. M. 1989. Suppressive influence of Pasteuria penetrans in Georgia soils on reproduction of Meloidogyne arenaria. Journal of Nematology 21:574.

Niblack, T. L., and Hussey, R. S. 1985. Extracting nematodes from soil and plant tissue. Pp. 201206 in B. M. Zuckerman, W. F. Mai, and M. B. Harrison, eds. Plant nematology laboratory manual. Amherst: The University of Massachusetts Agricultural Experiment Station.

Nishizawa, T. 1984. Effects of two isolates of Bacillus penetrans for control of root-knot nematodes and cyst nematodes. Proceedings First International Congress of Nematology 60-61.

Nishizawa, T. 1986. On an isolate of Pasteuria penetrans parasitic to cyst nematodes. Revue de Nèmatologie 9:303-304.

Nishizawa, T. 1987. A decline phenomenon in a population of the upland cyst nematode, Heterodera elachista, caused by a bacterial parasite, Pasteuria penetrans. Journal of Nematology 19:546.

Noel, G. R., and Stanger, B. A. 1994. First report of Pasteuria sp. attacking Heterodera glycines in North America. Supplement to Journal of Nematology 26:612-615. 
Noel, G. R., Atibalentja, N., and Bauer, S. J. 2010. Suppression of Heterodera glycines in a soybean field artificially infested with Pasteuria nishizawae. Nematropica 40:41-52.

Nordmeyer, D. 1992. The search for novel nematicidal compounds. Pp. 281-293 in F. J. Gommers and P. W. Th. Maas, eds. Nematology from molecule to Ecosystem. Scotland: European Society of Nematologists.

Norton, D. C. 1978. Ecology of plant-parasitic nematodes. New York: John Wiley and Sons.

Oka Y., Tkachi, N., Shuker, S., and Yerumiyahu, U. 2007. Enhanced nematicidal activity of organic and inorganic ammonia-releasing amendments by Azadirachta indica extracts. Journal of Nematology 39:9-16.

Oostendorp, M., Dickson, D. W., and Mitchell, D. J. 1990. Host range and ecology of isolates of Pasteuria spp. from the southeastern United States. Journal of Nematology 22:525-531.

Oostendorp, M., Dickson, D. W., and Mitchell, D. J. 1991a. Population development of Pasteuria penetrans on Meloidogyne arenaria. Journal of Nematology 23:58-64.

Oostendorp, M., Hewlett, T. E., Dickson, D. W., and Mitchell, D. J. 1991b. Specific gravity of spores of Pasteuria penetrans and extraction of spore-filled nematodes from soil. Journal of Nematology 23:729-732.

Orajay, J. I. 2009. Population dynamics of Pasteuria penetrans in a peanut field and description of a Pasteuria isolate infecting Mesocriconema ornatum. Dissertation presented to the University of Florida Graduate School, Gainesville, Florida.

Pal, K. K., and McSpadden Gardener, B. 2006. Biological control of plant pathogens. The Plant Health Instructor. The American Phytopathological Society. DOI: 10.1094/PHI-A-2006-1117-02

Panaccione, D. G., Kotcon, J. B., Schardl, C. L., Johnson, R. D., and Morton, J. B. 2006. Ergot alkaloids are not essential for endophytic fungus-associated population suppression of the lesion nematode, Pratylenchus scribneri, on perennial ryegrass. Nematology 8:583-590.

DOI: $10.1163 / 156854106778614074$

Pasteuria Bioscience, Inc. 2009. Econem ${ }^{\mathrm{TM}}$ receives EPA registration as first Pasteuria product for sting nematode control in turf. Press Release. Alachua, Florida. 
Pimentel, D. 2005. Environmental and economic costs of the application of pesticides primarily in the United States. Environment, Development and Sustainability 7:229-252.

DOI: $10.1007 / \mathrm{s} 10668-005-7314-2$

Pimentel, D., Hepperly, P., Hanson, J., Douds, D., and Seidel, R. 2005. Environmental, energetic, and economical comparisons of organic and conventional farming systems. BioScience 55:573-582. DOI: 10.1641/0006-3568(2005)055[0573:EEAECO]2.0.CO;2

Pokharel, R., and Zimmerman, R. 2010. Nematode community analysis as a soil health indicator in organic versus conventionally managed peaches. Journal of Nematology 42:264.

Potter, J. W., and Olthof, Th. H. A. 1993. Nematode pests of vegetable crops. Pp. 171-207 in K. Evans, D. L. Trudgill, and J. M. Webster, eds. Plant parasitic nematodes in temperate agriculture. Wallingford: CAB International.

Preston, J. F., Dickson, D. W., Maruniak, J. E., Nong, G., Brito, J. A., Schmidt, L. M., and Giblin-Davis, R. M. 2003. Pasteuria spp.: Systematics and phylogeny of these bacterial parasites of phytopathogenic nematodes. Journal of Nematology 35:198-207.

Pyrowolakis, A., Westphal, A., Sikora, R. A., and Becker, J. O. 2002. Identification of root-knot nematode suppressive soils. Applied Soil Ecology 19:51-56.

DOI: 10.1016/S0929-1393(01)00170-6

Rao, M. S., Parvatha Reddy, P., and Nagesh, M. 1997. Integration of Paecilomyces lilacinus with Neem leaf suspension for the management of root-knot nematodes on eggplant. Nematologia Mediterranea 25:249-252.

Reganold, J. P., Glover, J. D., Andrews, P. K., and Hinman, H. R. 2001. Sustainability of three apple production systems. Nature 410:926-929. DOI: 10.1038/35073574

Rimé, D., Nazaret, S., Gourbiere, F., Cadet, P., and Moenne-Loccoz, Y. 2003. Comparison of sandy soils suppressive or conducive to ectoparasitic nematode damage on sugarcane. Phytopathology 93:1437-1444. DOI: 10.1094/PHYTO.2003.93.11.1437

Saeed, I. A. M., Macguidwin, A. E., and Rouse, D. I. 1998. Effect of initial nematode population density on the interaction of Pratylenchus penetrans and Verticillium dahliae on 'Russet Burbank' potato. Journal of Nematology 30:100-107. 
Sasser, J. N., and Freckman, D. W. 1987. A world perspective on nematology: The role of society. Pp. 7-14 in J. A. Veech and D. W. Dickson, eds. Vistas on nematology. Hyattsville: Society of Nematologists.

Sayre, R. M. 1986. Pathogens for biological control of nematodes. Crop Protection 5:268-276. DOI: $10.1016 / 0261-2194(86) 90062-1$

Sayre, R. M., and Starr, M. P. 1985. Pasteuria penetrans (ex Thorne, 1940) nom. rev., comb. n., sp. n., a mycelial and endospore-forming bacterium parasitic in plant-parasitic nematodes. Proceedings of the Helminthological Society of Washington 52:149-165.

Sayre, R. M., and Starr, M. P. 1988. Bacterial diseases and antagonisms of nematodes. Pp. 59101 in G. O. Poinar, Jr., and H.-B. Jonson, eds. Diseases of nematodes. Boca Raton: CRC Press.

Sayre, R. M., and Wergin, W. P. 1977. Bacterial parasite of a plant nematode: Morphology and ultrastructure. Journal of Bacteriology 129:1091-1101.

Sayre, R. M., Adams, J. R., and Wergin, W. P. 1979. Bacterial parasite of a Cladoceran: Morphology, development in vivo, and taxonomic relationships with Pasteuria ramosa Metchnikoff 1888. International Journal of Systematic Bacteriology 29:252-262.

DOI: $10.1099 / 00207713-29-3-252$

Sayre, R. M., Gherna, R. L., and Wergin, W. P. 1983. Morphological and taxonomic reevaluation of Pasteuria ramosa Metchnikoff 1888 and "Bacillus penetrans" Mankau 1975. International Journal of Systematic Bacteriology 33:636-649. DOI: 10.1099/00207713-33-3-636

Sayre, R. M., Starr, M. P., Golden, A. M., Wergin, W. P., and Endo, B. Y. 1988. Comparison of Pasteuria penetrans from Meloidogyne incognita with a related mycelial and endospore-forming bacterial parasite from Pratylenchus brachyurus. Proceedings of the Helminthological Society of Washington 55:28-49.

Sayre, R. M., Wergin, W. P., Nishizawa, T., and Starr, M. P. 1991a. Light and electron microscopical study of a bacterial parasite from the cyst nematode, Heterodera glycines. Journal of the Helminthological Society of Washington 58:69-81.

Sayre, R. M., Wergin, W. P., Schmidt, J. M., and Starr, M. P. 1991b. Pasteuria nishizawae sp. nov., a mycelial and endospore-forming bacterium parasitic on cyst nematodes of genera Heterodera and Globodera. Research in Microbiology 142:551-564.

DOI: 10.1016/0923-2508(91)90188-G 
Schmidt, L. M., Mouton, L., Nong, G., Ebert, D., and Preston, J. F. 2008. Genetic and immunological comparison of the cladoceran parasite Pasteuria ramosa with the nematode parasite Pasteuria penetrans. Applied and Environmental Microbiology 74:259-264. DOI: 10.1128/AEM.01778-07

Schmidt, L. M., Hewlett, T. E., Green, A., Simmons, L. J., Kelley, K., Doroh, M., and Stetina, S. R. 2010. Molecular and morphological characterization and biological control capabilities of a Pasteuria ssp. parasitizing Rotylenchulus reniformis, the reniform nematode. Journal of Nematology 42:207-217.

Serracin, M., Schuerger, A. C., Dickson, D. W., and Weingartner, D. P. 1997. Temperaturedependent development of Pasteuria penetrans in Meloidogyne arenaria. Journal of Nematology 29:228-238.

Sharma, R. D., and Stirling, G. R. 1991. In vivo mass production systems for Pasteuria penetrans. Nematologica 37:483-484. DOI: 10.1163/187529291X00475

Sher, S. A., and Allen, M. W. 1953. Revision of the genus Pratylenchus (Nematoda: Tylenchidae). Pp. 441-470 in A. H. Miller, R. M. Eakin, and C. Stern, eds. University of California Publications in Zoology. Berkeley: University of California Press.

Shipton, P. J., Cook, R. J., and Sitton, J. W. 1973. Occurrence and transfer of a biological factor in soil that suppresses Take-all of wheat in Eastern Washington. Phytopathology 63:511-517. DOI: 10.1094/Phyto-63-511

Shukla, P. K., Haseeb, A., and Srivastava, N. K. 1997. The relation between soil pH and the reproduction/damage potential of Pratylenchus thornei on growth and oil yield of Mentha spicata. Nematologia Mediterranea 25:25-29.

Shurtleff, M. C., and Averre, III, C. W. 2000. Diagnosing plant diseases caused by nematodes. St. Paul: The American Phytopathological Society.

Sikora, R. A. 1992. Management of the soil antagonistic potential in agro-ecosystems for nematode control. Pp. 249-256 in F. J. Gommers and P. W. Th. Maas, eds. Nematology from molecule to ecosystem. Scotland: European Society of Nematologists.

Smiley, R. W., Sheedy, J. G., and Easley, S. A. 2008. Vertical distribution of Pratylenchus spp. in silt loam soil and Pacific Northwest dryland crops. Plant Disease 92:1662-1668.

DOI: 10.1094/PDIS-92-12-1662 
Sooby, J., Landeck, J., and Lipson, M. 2007. The Organic Farming Research Foundation's 2007 national organic research agenda: Soils, pests, livestock, genetics. Outcomes from the Scientific Congress on Organic Agricultural Research (SCOAR). Santa Cruz: Organic Farming Research Foundation.

Spaull, V. W. 1984 Observations on Bacillus penetrans infecting Meloidogyne in sugarcane fields in South Africa. Revue de Nèmatologie 7:277-282.

Starr, M. P., and Sayre, R. M. 1988. Pasteuria thornei sp. nov. and Pasteuria penetrans sensu stricto emend., mycelial and endospore-forming bacteria parasitic, respectively, on plantparasitic nematodes of the genera Pratylenchus and Meloidogyne. Annales de l'Institut Pasteur Microbiologie 139:11-31. DOI: 10.1016/0769-2609(88)90094-4

Stevens, G. N., and Stuart, R. J. 2008. The ecological complexities of biological control: Trophic cascades, spatial heterogeneity, and behavioral ecology. Journal of Nematology 40:59-60.

Stirling, G. R. 1985. Host specificity of Pasteuria penetrans within the genus Meloidogyne. Nematologica 31:203-209. DOI: 10.1163/187529285X00265

Stirling, G. R. 1992. Outlook for biocontrol. Pp. 257-265 in F. J. Gommers and P. W. Th. Maas, eds. Nematology from molecule to ecosystem. Scotland: European Society of Nematologists.

Stirling, G. R., and Wachtel, M. F. 1980. Mass production of Bacillus penetrans for the biological control of root-knot nematodes. Nematologica 26:308-312.

DOI: $10.1163 / 187529280 X 00260$

Stirling, G. R., Bird, A. F., and Cakurs, A. B. 1986. Attachment of Pasteuria penetrans spores to the cuticles of root-knot nematodes. Revue de Nèmatologie 9:251-260.

DOI: $10.1163 / 002925990 X 00211$

Stirling, G. R., Sharma, R. D., and Perry, J. 1990. Attachment of Pasteuria penetrans spores to the root knot nematode Meloidogyne javanica in soil and its effects on infectivity. Nematologica 36:246-252. DOI: 10.1163/002925990X00211

Sturhan, D., Winkelheide, R., Sayre, R. M., and Wergin, W. P. 1994. Light and electron microscopical studies of the life cycle and developmental stages of a Pasteuria isolate parasitizing the pea cyst nematode, Heterodera goettingiana. Fundamental and Applied Nematology 17:29-42. 
Sturhan, D., Shutova, T. S., Akimov, V. N., and Subbotin, S. A. 2005. Occurrence, hosts, morphology, and molecular characterisation of Pasteuria bacteria parasitic in nematodes of the family Plectidae. Journal of Invertebrate Pathology 88:17-26. DOI: 10.1016/j.jip.2004.11.001

Thomason, I. J. 1987. Challenges facing nematology: Environmental risks with nematicides and the need for new approaches. Pp. 469-476 in J. A. Veech and D. W. Dickson, eds. Vistas on nematology. Hyattsville: Society of Nematologists.

Thorne, G. 1940. Duboscqia penetrans n. sp. (Sporozoa, Microsporidia, Nosematidae), a parasite of the nematode Pratylenchus pratensis (de Man) Filipjev. Proceedings of the Helminthological Society of Washington 7:51-53.

Tian, B., Yang, J., and Zhang, K. 2007. Bacteria used in the biological control of plant-parasitic nematodes: Populations, mechanisms of action, and future prospects. FEMS Microbiology Ecology 61:197-213. DOI:10.1111/j.1574-6941.2007.00349.x

Timper, P., and Brodie, B. B. 1994. Effect of Hirsutella rhossiliensis on infection of potato by Pratylenchus penetrans. Journal of Nematology 26:304-307.

Townshend, J. L., Potter, J. W., and Willis, C. B. 1978. Ranges and distribution of species of Pratylenchus in Northeastern North America. Canadian Plant Disease Survey 58:80-82.

United States Department of Agriculture, Agricultural Marketing Service, National Organic Program. 2010. http://www.ams.usda.gov/AMSv1.0/nop

United States Department of Agriculture, Economic Research Service. July 5, 2015. http://www.ers.usda.gov/topics/natural-resources-environment/organic-agriculture/organicmarket-overview.aspx

United States Department of Agriculture, Natural Resources Conservation Service. 2009. Web Soil Survey. http://websoilsurvey.sc.egov.usda.gov/App/HomePage.htm

Verdejo-Lucas, S. 1992. Seasonal fluctuations of Meloidogyne spp. and the Pasteuria penetrans group in kiwi orchards. Plant Disease 76:1275-1279. DOI: 10.1094/PD-76-1275

Weibelzahl-Fulton, E., Dickson, D. W., and Whitty, E. B. 1996. Suppression of Meloidogyne incognita and M. javanica by Pasteuria penetrans in field soil. Journal of Nematology 28:43-49. 
Westerdahl, B. B., Giraud, D., Etter, S., Riddle, L. J., Radewalk, J. D., Anderson, C. A., and Darso, J. 2003. Management options for Pratylenchus penetrans in Easter lily. Journal of Nematology 35:443-449.

Westphal, A. 2005. Detection and description of soils with specific nematode suppressiveness. Journal of Nematology 37:121-130.

Westphal, A., and Becker, J. O. 2000. Transfer of biological soil suppressiveness against Heterodera schachtii. Phytopathology 90:401-406. DOI: 10.1094/PHYTO.2000.90.4.401

Willis, C. B. 1972. Effects of soil pH on reproduction of Pratylenchus penetrans and forage yield of alfalfa. Journal of Nematology 4:291-295.

Zunke, U. 1990. Observations on the invasion and endoparasitic behavior of the root lesion nematode Pratylenchus penetrans. Journal of Nematology 22:309-320. 